\title{
Alzheimer's Disease-Like Pathology Induced by Amyloid- $\beta$ Oligomers in Nonhuman Primates
}

\author{
Leticia Forny-Germano, ${ }^{1,2}$ Natalia M. Lyra e Silva, ${ }^{1 \star}$ André F. Batista, ${ }^{1 *}$ Jordano Brito-Moreira, ${ }^{1}$ Matthias Gralle, ${ }^{1}$ \\ Susan E. Boehnke, ${ }^{3}$ Brian C. Coe, ${ }^{3}$ Ann Lablans, ${ }^{3}$ Suelen A. Marques, ${ }^{4}$ Ana Maria B. Martinez, ${ }^{2}$ William L. Klein, ${ }^{5}$ \\ - $J e a n-C h r i s t o p h e ~ H o u z e l,{ }^{2}$ Sergio T. Ferreira, ${ }^{1}$ Douglas P. Munoz, ${ }^{3} \dagger$ and Fernanda G. De Felice ${ }^{1} \dagger$ \\ ${ }^{1}$ Institute of Medical Biochemistry Leopoldo de Meis and ${ }^{2}$ Institute of Biomedical Sciences, Federal University of Rio de Janeiro, Rio de Janeiro, RJ 21944- \\ 590, Brazil, ${ }^{3}$ Centre for Neuroscience Studies, Queen's University, Kingston, Ontario K7L 3N6, Canada, ${ }^{4}$ Departament of Neurobiology, Institute of Biology, \\ Fluminense Federal University, Niterói, RJ, 24020-140 Brazil, and ${ }^{5}$ Department of Neurobiology and Physiology, Northwestern University, Evanston, \\ Illinois 60208
}

\begin{abstract}
Alzheimer's disease $(\mathrm{AD})$ is a devastating neurodegenerative disorder and a major medical problem. Here, we have investigated the impact of amyloid- $\beta(\mathrm{A} \beta)$ oligomers, $\mathrm{AD}$-related neurotoxins, in the brains of rats and adult nonhuman primates (cynomolgus macaques). Soluble $\mathrm{A} \beta$ oligomers are known to accumulate in the brains of $\mathrm{AD}$ patients and correlate with disease-associated cognitive dysfunction. When injected into the lateral ventricle of rats and macaques, $A \beta$ oligomers diffused into the brain and accumulated in several regions associated with memory and cognitive functions. Cardinal features of $\mathrm{AD}$ pathology, including synapse loss, tau hyperphosphorylation, astrocyte and microglial activation, were observed in regions of the macaque brain where $\mathrm{A} \beta$ oligomers were abundantly detected. Most importantly, oligomer injections induced AD-type neurofibrillary tangle formation in the macaque brain. These outcomes were specifically associated with $\mathrm{A} \beta$ oligomers, as fibrillar amyloid deposits were not detected in oligomer-injected brains. Human and macaque brains share significant similarities in terms of overall architecture and functional networks. Thus, generation of a macaque model of $\mathrm{AD}$ that links $\mathrm{A} \beta$ oligomers to tau and synaptic pathology has the potential to greatly advance our understanding of mechanisms centrally implicated in AD pathogenesis. Furthermore, development of disease-modifying therapeutics for AD has been hampered by the difficulty in translating therapies that work in rodents to humans. This new approach may be a highly relevant nonhuman primate model for testing therapeutic interventions for AD.
\end{abstract}

Key words: Alzheimer's disease; amyloid- $\beta$ oligomers; nonhuman primate; synapse loss; tau pathology

\section{Introduction}

Alzheimer's disease (AD) is histopathologically characterized by the presence of extracellular fibrillar amyloid- $\beta(\mathrm{A} \beta)$ deposited

\section{Received March 31, 2014; revised Aug. 27, 2014; accepted Aug. 30, 2014}

Author contributions: L.F.-G., J.-C.H., S.T.F., D.P.M., and F.G.D.F. designed research; L.F.-G., N.M.L.e.S., A.F.B., J.B.-M., M.G., A.L., S.A.M., D.P.M., and F.G.D.F. performed research; B.C.C., A.M.B.M., and W.L.K. contributed unpublished reagents/analytic tools; L.F.-G., N.M.L.e.S., A.F.B., J.-C.H., S.T.F., and F.G.D.F. analyzed data; L.F.-G., N.M.L.e.S., A.F.B., S.E.B., S.T.F., D.P.M., and F.G.D.F. wrote the paper.

This work was supported by grants from Human Frontiers Science Program and the John Simon Guggenheim Memorial Foundation (to FGF), National Institute for Translational Neuroscience (Brazil; to S.T.F. and F.G.D.F.), the Brazilian funding agencies ConselhoNacional de DesenvolvimentoCientífico e Tecnológico (CNPq) and Fundação de Amparo à Pesquisa do Estado do Rio de Janeiro (FAPERJ; to S.T.F. and F.G.D.F.), Canadian Institutes for Health Research (Grant MOP-38854 to D.P.M. and F.G.D.F.) and Canada Research Chair Program (D.P.M.). NLS and AFB are supported by CNPq predoctoral fellowships. J.B.M. was supported by a CNPq predoctoral fellowship. LFG is supported by a postdoctoral fellowship from FAPERJ/Coordenação de Aperfeiçoamentode Pessoal de Nivel Superior. We thank Edil Saturato da Silva Filho, and Dr. Claudia P. Figueiredo (Federal University of Rio de Janeiro, Brazil) for technical advice on macaque brain processing and advice on immunohistochemical analysis, respectively. The following anti-tau antibodies were a generous gift from Dr Peter Davies (Albert Einstein College of Medicine, Bronx, NY): ALZ-50, MC-1, CP13, and PHF-1.

W.L.K. is cofounder of Acumen Pharmaceuticals, which has been licensed by Northwestern University to develop ADDL (A $\beta$ oligomer) technology for Alzheimer's therapeutics and diagnostics.

*N.M.L.S. and A.F.B. contributed equally to this work.

tD.P.M. and F.G.D.F. are joint senior authors.

Correspondence should be addressed to either of the following: Fernanda G. De Felice, Institute of Medical Biochemistry, CCS, Room H2-019, Federal University of Rio de Janeiro, Rio de Janeiro, RJ 21944-590, Brazil, E-mail: felice@bioqmed.ufri.br; or Douglas P.Munoz; Centre for Neuroscience Studies, Queen's University, Kingston, Ontario K7L 3N6, Canada, E-mail:doug.munoz@queensu.ca. in plaques and intraneuronal neurofibrillary tangles (NFTs) consisting of aggregated hyperphosphorylated tau (phospho-tau) (Querfurth and LaFerla, 2010). Knowledge on mechanisms of $\mathrm{AD}$ pathogenesis and on preclinical evaluation of treatments directed at $\mathrm{A} \beta$ or phospho-tau have come from pathology, genetics, and various transgenic rodent $\mathrm{AD}$ models (Braak and Braak, 1991; LaFerla and Oddo, 2005; Goedert and Spillantini, 2006; Yoshiyama et al., 2007). Due to the complexity of the neuropathology spectrum of $\mathrm{AD}$, such transgenic models are very useful for studying some, but not all, disease aspects. In particular, NFTs are generally not present in transgenic models expressing mutant forms of human $\mathrm{A} \beta$ precursor protein (APP) and/or presenilins. A significant advance in the field came from development of transgenic rodent models that presents tau pathology (Oddo et al., 2003a,b; McGowan, et al., 2006; Chabrier et al., 2012; Cohen et al., 2013). Most of these models harbor not only mutations in APP and/or presenillin1 but also a mutation in tau. The latter is associated with other tauopathies, such as frontotemporal dementia (Spillantini et al., 1998; Götz and Ittner, 2008), but is not part of $\mathrm{AD}$ pathology. In addition, the most frequently used transgenic $\mathrm{AD}$ mouse models carry mutations that are associated 
with early onset familial forms of human $\mathrm{AD}$, which only account for $<5 \%$ of cases. The vast majority of $\mathrm{AD}$ cases are sporadic with poorly understood etiology.

The pathogenic trigger of AD has been proposed to comprise soluble $\mathrm{A} \beta$ oligomers (A $\beta O s) . A \beta O s$, synaptotoxins that accumulate in $\mathrm{AD}$ brains, have been implicated in key aspects of AD (DaRochaSouto et al., 2011; Ferreira and Klein, 2011; Selkoe, 2011; Chabrier et al., 2012; Finch and Austad, 2012). In cell-based systems and animal models, $\mathrm{A} \beta \mathrm{O}$ s are associated with $\mathrm{AD}$ hallmarks, including phospho-tau, oxidative stress, and synapse loss (De Felice et al., 2007, 2008; Jin et al., 2011). Of clinical relevance, individuals who died without signs of cognitive and intellectual deterioration presented abundant brain amyloid deposits, whereas conversely, individuals lacking deposits exhibited varying degrees of cognitive deterioration (Negash et al., 2011).

Given the proposed roles of soluble $\mathrm{A} \beta$ in $\mathrm{AD}$ and the limitations of currently available animal models (Mucke and Selkoe, 2012), we here investigated whether intracerebroventricular (i.c.v.) injections of $\mathrm{A} \beta \mathrm{O}$ s in the brains of adult cynomolgus macaques might induce AD-like pathology. Macaques are old-world nonhuman primates typically used as models of human sensory, cognitive, and motor processing due to considerable similarity of higher brain structures (Orban et al., 2004; Sereno and Tootell, 2005; Kaas, 2013; Van Essen, 2013). We first developed the experimental approach in rats before moving to the complexity of the macaque system. Results demonstrate that $\mathrm{A} \beta \mathrm{O}$ s rapidly diffused and were detected in neurons in a regionally specific manner in rats and macaques. Whereas $\mathrm{A} \beta \mathrm{O}$ s were abundantly detected in the neocortex, hippocampus, striatum, and amygdala, regions such as the brainstem and cerebellum presented markedly fewer

$\mathrm{A} \beta \mathrm{O}$-positive neurons. In the macaque brain, $\mathrm{A} \beta \mathrm{O}$ s induce astrocyte and microglial activation, synapse loss, phospho-tau and NFTs formation, in regions associated with cognitive functions and operant behavior. Collectively, the results provide evidence on the impact of $\mathrm{A} \beta \mathrm{O}$ s in the primate brain and establish a novel macaque model that presents central $\mathrm{AD}$ neuropathological correlates.

\section{Materials and Methods}

$A \beta O$ s. $\mathrm{A} \beta \mathrm{O}$ s were prepared from synthetic $\mathrm{A} \beta_{1-42}$ peptide (American Peptide) as described previously (Lambert et al., 1998). The peptide was first solubilized in hexafluoroisopropanol, and the solvent was evaporated to produce dried films, which were subsequently dissolved in sterile anhydrous dimethylsulfoxide (DMSO) to make a $5 \mathrm{~mm}$ solution. This solution was diluted to $100 \mu \mathrm{M}$ in ice-cold PBS and incubated for $16 \mathrm{~h}$ at $4^{\circ} \mathrm{C}$. The preparation was centrifuged at $14,000 \times g$ for $10 \mathrm{~min}$ at $4^{\circ} \mathrm{C}$ to remove insoluble aggregates (protofibrils and fibrils), and the superna-

A
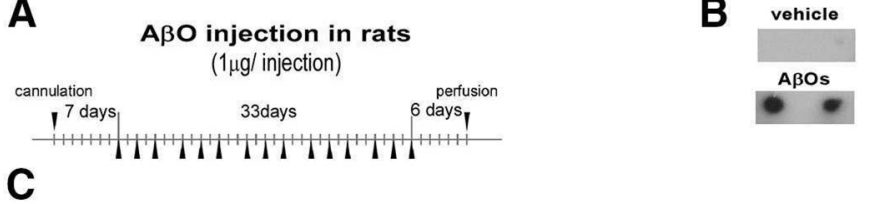

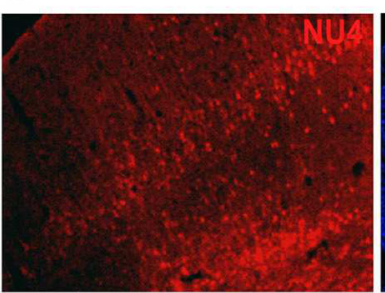

D
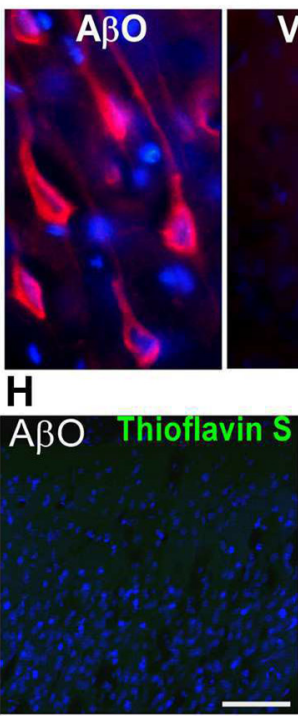

Figure 1. $A \beta 0$ s diffuse and accumulate in the frontal cortex of rats. $\boldsymbol{A}$, Chronogram representing the protocol for intracerebroventricular injections of $A \beta 0$ s in rats $(n=15$, vehicle; $n=13 \mathrm{~A} \beta 0 \mathrm{~s})$. $\boldsymbol{B}$, Dot blot of homogenates from the frontal cortex of rats receiving intracerebroventricular injections of vehicle or $A \beta 0$ s (duplicate results from representative rats are shown). (C) Repre作 served in vehicle-injected rat brains $(n=13)$. Scale bar, $25 \mu \mathrm{m}$. $\boldsymbol{F}$, Micrograph of the frontal cortex from a rat that received $A \beta 0$ ( labeling (red). Scale bar, $5 \mu \mathrm{m}$. $\boldsymbol{H}, \boldsymbol{I}$, Representative micrographs of thioflavin-S staining in the hippocampus of a rat injected with $\mathrm{A} \beta 0 \mathrm{~s}(\boldsymbol{H})$, and in the hippocampus of the APP/PS1 mouse. Scale bar, $500 \mu \mathrm{m}$; inset, $50 \mu \mathrm{m}$; I). Scale bar (in $\boldsymbol{H}$ ), $100 \mu \mathrm{m}$. J, NU4 labeling in the frontal cortex of the APPSwe,PS1 $\Delta$ E9 transgenic mouse reveals abundant amyloid plaques (red). Cell nuclei revealed by DAPI staining. Scale bar, $500 \mu \mathrm{m}$. tants containing soluble $\mathrm{A} \beta \mathrm{O}$ s were stored at $4^{\circ} \mathrm{C}$. Protein concentration was determined using the Bicinchoninic acid assay (BCA; Thermo Scientific Pierce). Preparations were routinely characterized by HPLC sizeexclusion chromatography under nondenaturing conditions and by SDS-PAGE/Western blot using anti-A $\beta$ 6E10 (Covance) and anti-A $\beta O$ NU4 (Lambert et al., 2007) antibodies. Size exclusion chromatography (SEC) analysis reveals that $\mathrm{A} \beta$ oligomers preparations comprise a mixture of high-molecular-weight (molecular masses ranging from 80 to 150 $\mathrm{kDa}$ ) and low-molecular-weight (average molecular mass, $10 \mathrm{kDa}$ ) oligomers, and are virtually devoid of $\mathrm{A} \beta$ monomers. Lack of monomers in $\mathrm{A} \beta \mathrm{O}$ preparations detected SEC is consistent with the high tendency of $\mathrm{A} \beta_{1-42}$ to self-aggregate in aqueous medium, and also with previously reported SEC profiles of oligomers prepared using the same protocol we used. A complete description of the biophysical/biochemical characterization of the preparation of $\mathrm{A} \beta \mathrm{O}$ s we used in the current work was described in previous work from our group (Chromy et al., 2003; De Felice et al., 2007, 2008; Sebollela et al., 2012; Figueiredo et al., 2013). Oligomers were prepared and immediately used in the procedures described below. 
A

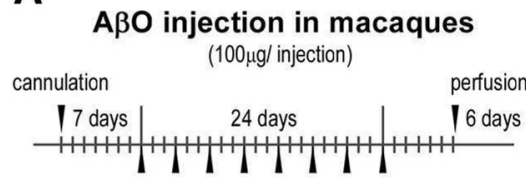

C

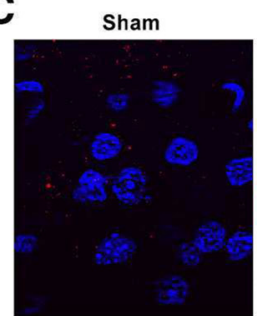

$\mathrm{A} \beta \mathrm{Os}$

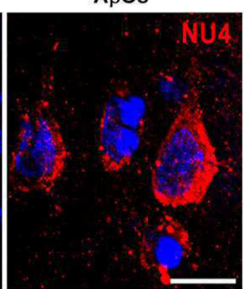

E

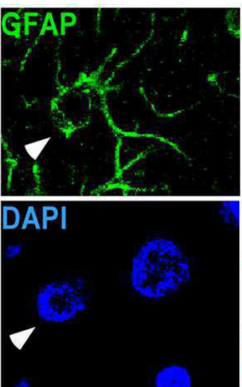

F
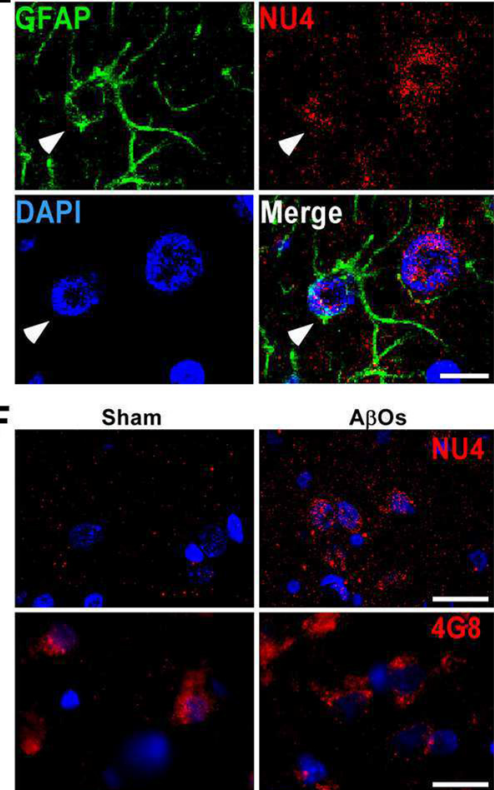

A $\beta O s$
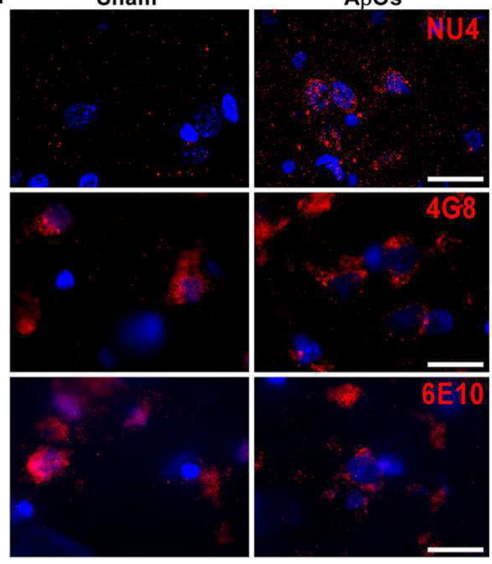

Figure 2. $A \beta 0$ s diffuse and accumulate in the frontal cortex of macaques. $A, B$, Chronogram representing the administration and amount of injections of $A \beta 0$ s in macaques ( $n=3$ sham; $n=4 A \beta 0$ s). $C, A \beta 0$ binding (red) in the frontal cortex of a macaque that received $A \beta 0$ injections. No $A \beta 0$ immunostaining was detected in the frontal cortex of the sham-operated macaques. Scale bar, $25 \mu \mathrm{m}$. D, Micrographic reconstruction of a section through the frontal cortex from a macaque that received intracerebroventricular injections of A $\beta 0$ s labeled with NU4 (red). Cell nuclei are labeled by DAPI. Neocortical layers I-VI and white matter (WM) are indicated. Right, High-magnification image of layers III-V, demonstrating the presence of A $\beta 0$-positive cells (NU4 antibody, red; Lambert et al., 2007). Scale bar, $100 \mu \mathrm{m}$. $\boldsymbol{E}$, Confocal micrograph of the frontal cortex from a macaque that received $A \beta 0$ injections shows colocalization between a cell stained for GFAP (green) and A $\beta 0$ s (red, NU4 antibody). Scale bar, $10 \mu \mathrm{m} . \boldsymbol{F}$, Representative micrographs of the frontal cortex of macaques demonstrate the pattern of immunolabeling using and the antioligomer antibody NU4 and the anti-A $\beta$ antibodies $4 \mathrm{G} 8$ and $6 \mathrm{E} 10$.

Intracerebroventricular injection of AßOs. Rats. Twenty-eight male Wistar rats (Rattus norvegicus) aged 3 months (body weights: $300-400 \mathrm{~g}$ ) were used. All procedures were approved by the Federal University of Rio de Janeiro Animal Care Committee (protocol numbers IBqM 041 and IBqM 019) and were in full compliance with the National Institute of Health Guide for Care and Use of Laboratory Animals. Rats were anesthetized with intramuscular valium $(1.5 \mathrm{mg} / \mathrm{kg})$, xylazine $(5 \mathrm{mg} / \mathrm{kg})$, ketamine $(100 \mathrm{mg} / \mathrm{kg})$, and atropine $(0.2 \mathrm{mg} / \mathrm{kg})$. Analgesia was maintained by intramuscular ketamine ad libitum. Rats were placed in a stereotaxic apparatus (Horsley-Clarke) and two craniotomies (diameter: $1.2 \mathrm{~mm}$ ) were performed before insertion of two cannulas (Plastics One) at fol- lowing coordinates: Anterior cannula (bregma: $-0.92 \mathrm{~mm}$; laterality: $1.5 \mathrm{~mm}$; depth: 3.5 $\mathrm{mm}$ ); posterior cannula (bregma: $-4.00 \mathrm{~mm}$; laterality: $1.5 \mathrm{~mm}$; depth: $3.5 \mathrm{~mm}$; Paxinos and Watson, 1997). After a recovery period of $7 \mathrm{~d}$, rats received intracerebroventricular injections of $1 \mu \mathrm{g} \mathrm{A} \beta \mathrm{Os}(n=13)$ or vehicle ( $2 \%$ DMSO in PBS; control group, $n=15$ ) in the anterior cannula. Injections were performed three times a week for 5 weeks (Fig. 1A). Rats were transcardially perfused with saline solution $0.9 \%$, followed by $4 \%$ paraformaldehyde. Brains were removed and coronal $40-\mu \mathrm{m}$ thick sections were obtained.

Macaques. Seven females cynomolgus macaques (Maccaca fascicularis, body weights: 4.7-7.0 kg) were used. Macaques were maintained at the Centre for Neuroscience at Queen's University (Kingston, Canada) under the close supervision of a lab animal technician and the Institute veterinarian. All procedures were approved by the Queen's University Animal Care Committee and were in full compliance with the Canada Council on Animal Care (Animal Care Protocol Original Munoz, 2011039-Or). All animals (3 sham animals, $4 \mathrm{~A} \beta \mathrm{O}$ animals) underwent a single surgical procedure to anchor a dental acrylic explant to the skull with Teflon or titanium screws. The explant included a chamber over a small midline craniotomy to access the lateral ventricles. Anesthesia was induced by ketamine (10-15 mg/ $\mathrm{kg}$, intramuscular) and diazepam (0.25-0.5 $\mathrm{mg} / \mathrm{kg}$, intramuscular). Animals were given glycopyrrolate $(0.013 \mathrm{mg} / \mathrm{kg})$ and were intubated. During surgery, anesthesia was maintained with isoflurane (1-3\%), while meloxicam $(0.2 \mathrm{mg} / \mathrm{kg})$ and cefazolin $(22 \mathrm{mg} /$ $\mathrm{kg}$ ) were also administered. Correct placement of the chamber was assessed by MRI. Three sham-operated macaques, 9- $(n=1)$ and 16years-old $(n=2)$, were used as controls and underwent the full surgical procedure but did not receive intracerebroventricular injection. After a recovery period of 2-4 weeks, four macaques, 9 - $(n=2)$ and 16-years-old $(n=2)$, had a guide cannula inserted into the lateral ventricle and held in place with a grid system in the chamber (Crist et al., 1988). They then received intracerebroventricular injections of $10-100 \mu \mathrm{g}$ of $\mathrm{A} \beta \mathrm{Os}(\sim 1$ injection per day every $3 \mathrm{~d}$ for up to $24 \mathrm{~d}$; Fig. $2 A$ ). Even though the experimental design involved injection of a fixed amount of $100 \mu \mathrm{g}$ of $\mathrm{A} \beta O$ s per injection in all macaques, it is important to note that in practice this amount was somewhat variable among animals due to procedural limitations at the moment of injection (including partial clogging of the cannulas and liquid reflux through the cannula following injection). Detailed information on the amount of $\mathrm{A} \beta \mathrm{O}$ effectively injected is present in Figure $2 B$. Approximately 1 week after completion of the experimental protocol, macaques were sedated with intramuscular ketamine $(10 \mathrm{mg} / \mathrm{kg})$, followed by intravenous sodium pentobarbital $(25 \mathrm{mg} / \mathrm{kg}$ ) and heparin. They were then perfused intracardially with PBS followed by $4 \%$ paraformaldehyde in PBS. Brains were removed and coronal 40- $\mu$ m-thick sections were obtained.

Immunohistochemistry. Immunohistochemistry was performed using free-floating sections in PBS containing 1\% Triton incubated with $0.1 \mathrm{M}$ citrate buffer, $\mathrm{pH}$, at $60^{\circ} \mathrm{C}$ for $5 \mathrm{~min}$. For detection of Tau phosphory- 
lated epitopes (tau-pSer ${ }^{396}$, MC-1, AT100, CP13, AT8, PHF-1, and Alz-50), sections were treated with $70 \%$ formic acid for $7 \mathrm{~min}$. For AT8, CP13, MC-1 (data not shown), and $\mathrm{Alz}-50$ the following steps were the same for immunofluorescence. Endogenous peroxidase was inactivated by incubation of sections with $3 \%$ hydrogen peroxide in methanol for $2 \mathrm{~h}$. Sections were then blocked with $5 \%$ bovine serum albumin (BSA) and 5\% normal goat serum in $1 \%$ Triton $\mathrm{X}-100$ for $3 \mathrm{~h}$ at room temperature. Primary antibodies were diluted in blocking solution and incubated with sections at $4^{\circ} \mathrm{C}$ for $16 \mathrm{~h}$, followed by incubation with biotinylated secondary antibody for $2 \mathrm{~h}$ at room temperature, and then processed using the Vectastain Elite ABC reagent (Vector Laboratories) according to the manufacturer's instructions. The sections were washed in PBS and developed using 3, 3'-diaminobenzidine (DAB; Sigma-Aldrich) in chromogen solution, and counterstained with Harris's hematoxylin (Merck). Slides were mounted with Entellan (Merck) and imaged on a Zeiss Axio Observer Z1 microscope. Omission of primary antibody was routinely used to certify absence of nonspecific labeling (data not shown).

For immunofluorescence analysis, tissue autofluorescence was quenched by incubation with $0.06 \%$ potassium permanganate for 10 $\mathrm{min}$ at room temperature. Sections were blocked in 5\% BSA and 5\% normal goat serum in $1 \%$ Triton X-100 for $3 \mathrm{~h}$ at room temperature. Primary antibodies were diluted in blocking solution and sections were incubated at $4^{\circ} \mathrm{C}$ for $16 \mathrm{~h}$, followed by incubation with AlexaFluor 555, AlexaFluor 594, and AlexaFluor 488-conjugated secondary antibodies ( $1: 1500)$ for $2 \mathrm{~h}$ at room temperature. Nuclei were stained with $4^{\prime}, 6$-diamidino-2-phenylindole (DAPI; Calbiochem) for 5 min. Slides were mounted with Prolong Gold Antifade with DAPI (Invitrogen) and imaged on a Zeiss Axio Observer Z1 microscope equipped with an Apotome module to minimize out-of-focus light. $Z$-stack projections from the frontal cortex of macaques (total area: $7 \mu \mathrm{m}$, for each image: $x=0,06 \mu /$ pixel, $y=0,06 \mu /$ pixel, $z=0,28$ $\mu /$ pixel). For synaptic puncta analyses, cells were observed with a Leica confocal microscope.

Antibodies. Antibodies used for immunohistochemistry were Tau-pSer ${ }^{396}$ (1:200; recognizes phosphorylation of Tau at serine residue 396, Santa Cruz Biotechnology, catalog \#sc-101815 RRID:AB_1129987); AT100 (1:70; recognizes phosphorylation of Tau at serine residue 212 and threonine residue 214, Thermo Scientific Pierce Protein Research Products, catalog \#MN1060 RRID:AB_223652); AT8 (1:200; Thermo Scientific Pierce Antibodies Cat\# MN1020 RRID:AB_223647). MC-1 (1:200, recognizes early conformational changes in tangle formation), CP13 (1:200; recognizes phosphorylation of Tau at serine residue 202); PHF- 1 (1:200; recognizes phosphorylation of Tau at serine residues 396 and 404), and Alz-50 (1:200; conformational antibody) were generous gifted by Dr Peter Davies (Albert Einstein College of Medicine, Bronx, NY). Synaptophysin (1:200, Sigma-Aldrich, catalog \#S5768, RRID: AB_477523), PSD-95 (1:200, Abcam, catalog \#ab18258, RRID:AB 444362); 4G8 (1: 200, Covance, catalog \#SIG-39220-200 RRID:AB_10174824), glial fibrillary acidic protein (GFAP, 1:500, Dako, catalog \#Z0334 RRID: AB_10013382), and IBA-1 (1:200, Abcam, catalog \#ab5076, RRID:
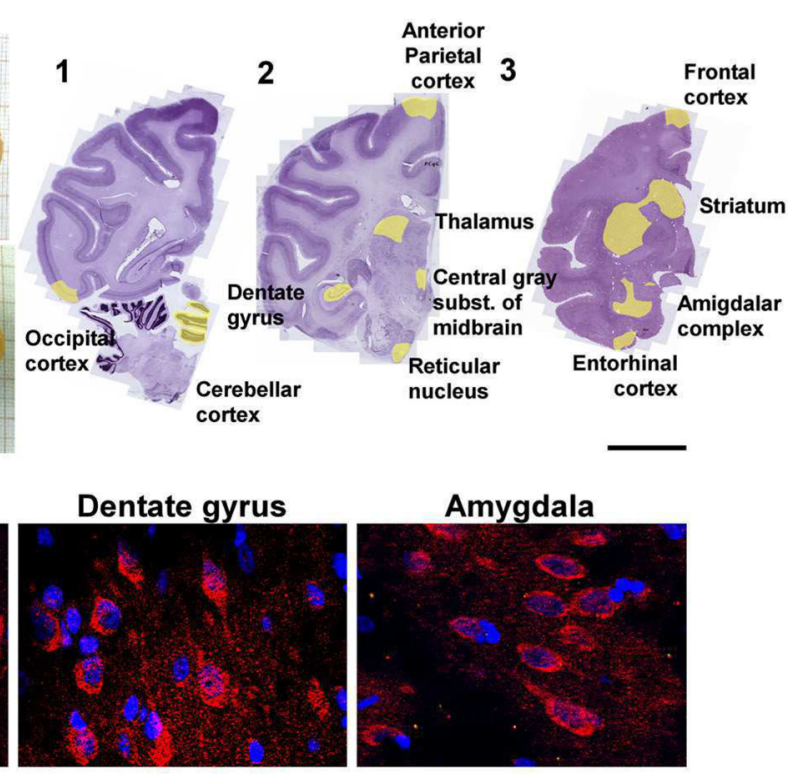

Midbrain

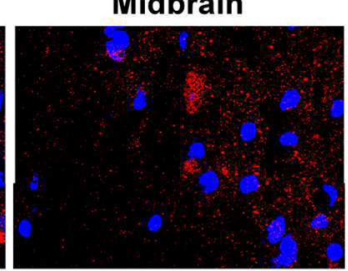

Cerebellar cortex

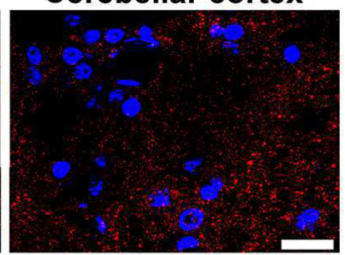

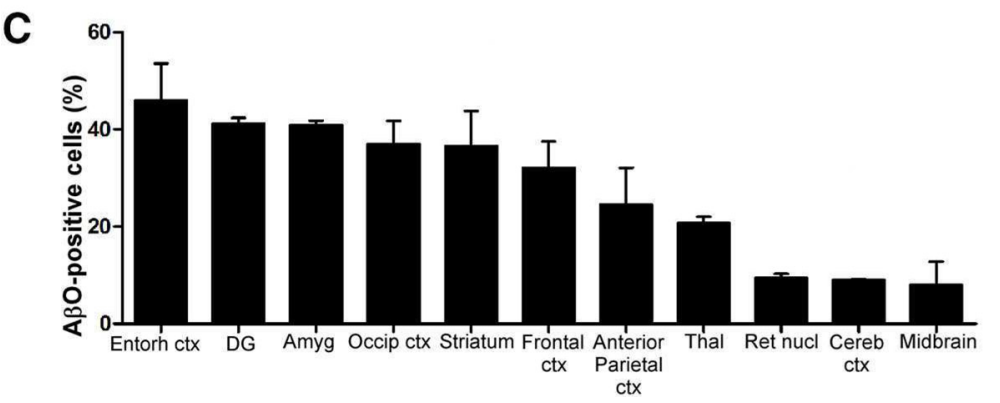

Figure 3. A $A 0$ s distribute into distinct brain areas and act as pathogenic ligands in macaques. $\boldsymbol{A}$, Left, Lateral and sagittal view images of macaque brains regions immunostained for $A \beta 0 \mathrm{~s}$. $A \beta 0$ s were labeled using the NU4 anti-oligomer $\mathrm{A} \beta 0$-positive cells in different brain regions $(n=3)$. Error bars are \pm SEM. Enth ctx, Enthorinal cortex; DG, dentate gyrus; Amy, amygdala; Occip ctx, occiptal cortex; Thal, thalamus; Ret Nucl, reticular nucleus; Cereb Ctx, cerebellar cortex.

AB_2224402). A $\beta$ O-selective NU4 mouse monoclonal antibody was gifted by Dr William Klein (Northwestern University, Evanston, IL). For Western Blotting the antibodies used were Tau-pSer ${ }^{396}$ (1:100; Santa Cruz Biotechnology, catalog \#sc-101815 RRID: AB_1129987). Total tau (Tau-5, 1:100, Abcam, catalog \#ab3931, RRID:AB_304171), 6 E10 (1: 1000, Covance, catalog \#SIG-39300-200 RRID:AB_10175290), and b-actin (1:1000, Abcam, catalog \#ab6276 RRID:AB_2223210). The secondary antibodies for immunohistochemistry were AlexaFluor 488 (Life Technologies, catalog \#A11034 RRID:AB_10562715), AlexaFluor 594 (Invitrogen, catalog \#A21424 RRID:AB_141780), and AlexaFluor 555 (Invitrogen, catalog \#A21424 RRID:AB_141780). For Western blotting the antibodies were as follows: goat anti-mouse IRDye800 (LI-COR Biosciences, catalog \#82708364, RRID:AB_10793856) or goat anti-rabbit IRDye 800 IgG (LI-COR Biosciences, catalog \#827-08365, RRID:AB_10796098).

Cytoarchitecture of brains. The cytoarchitecture of macaques (Martin and Bowden, 1996) and rat (Paxinos and Watson, 1997) brain slices was ana- 
Table 1. Brain regions analyzed following intracerebroventricular injections of $A \beta 0$ s

\begin{tabular}{|c|c|}
\hline Brain regions & Specific nomenclature for analyzed regions \\
\hline \multicolumn{2}{|l|}{ Macaque } \\
\hline Frontal cortex & Superior frontal gyrus (SFG) layers 3, 4, and 5 \\
\hline Anterior parietal cortex & Post central gyrus superior layers 3 and 4 \\
\hline Occipital cortex & Inferior occipital gyrus \\
\hline Entorhinal cortex & Entorhinal area \\
\hline Dentate gyrus of hippocampus & Polymorphic layer of the dentate gyrus (PoDG) and granular layer of the dentate gyrus (GrDG) \\
\hline Thalamus & Caudal Part of ventral lateral nucleus and caudal part of the ventral posterolateral nucleus \\
\hline Striatum & Caudate and putamen \\
\hline Amygdalar complex & Cortical nucleus amygdaloidal and basal amygdaloid nucleus \\
\hline Cerebellum & Cerebellar cortex \\
\hline Midbrain & Central gray substance of midbrain (CGMB) \\
\hline Reticular nucleus & Pontine nucleus (Pn), pontine caudal reticular nucleus (PnC), and pedunculopontine tegmental nucleus (PPTg) \\
\hline \multicolumn{2}{|r|}{$\mathrm{C}$} \\
\hline Frontal cortex & Secondary motor cortex (M2) layers 3 and 4 \\
\hline Anterior parietal cortex & Posterior portion of secondary somatosensory cortex (S1HL) layers 3 and 4 \\
\hline Occipital cortex & Medial parietal association cortex (MPta) and mediolateral area of secondary visual cortex (v2MM) layers 3 and 4 \\
\hline Dentate gyrus of hippocampus & Polymorphic layer of the dentate gyrus (PoDG) and granular layer of the dentate gyrus (GrDG) \\
\hline Thalamus & $\begin{array}{l}\text { Posterior complex of the thalamus (Po), ventrolateral portion of laterodorsal thalamic nucleus (LDVL), mediorostral portion of thalamic nucleus (LPMR), } \\
\text { ventral lateral nucleus }(\mathrm{VL})\end{array}$ \\
\hline Basal ganglia & Caudate, putamen, and globus pallidus \\
\hline Amygdalar complex & Basolateral amygdaloidal nucleus \\
\hline Cerebellum & Cerebellar cortex \\
\hline
\end{tabular}

lyzed by Nissl staining and coronal slice reconstructions were performed using the Virtual Tissue 2D module from Neurolucida (MBF Bioscience; Fig. 3A).

Thioflavin S staining. For macaque's brain sections, tissue autofluorescence was quenched by incubation with $0.06 \%$ potassium permanganate for $10 \mathrm{~min}$ at room temperature. Macaque and rodent sections were incubated in 1\% thioflavin S (Sigma-Aldrich) for $35 \mathrm{~min}$. Some sections were stained with DAPI to visualize the cell nucleus. Slides were mounted with Entellan and imaged on a Zeiss Axio Observer Z1 microscope. APPSwe,PS1 $\Delta \mathrm{E} 9$ mice on a C57BL/6 background (APP/PS1, 13- to 16month-old) were obtained from The Jackson Laboratory and used as positive controls for presence of $\mathrm{A} \beta$ deposits.

Image analysis. For $\mathrm{A} \beta \mathrm{O}$ s immunostaining in rats and macaques, $20-30$ images were acquired from each region of interest for each animal, with the same acquisition parameters. The percentage of $\mathrm{A} \beta \mathrm{O}$ reactivity was assessed by manual quantification of DAPI and NU-4-positive cells present in each region of interest. For neuropathology of macaque brains, tau-pSer ${ }^{396}$, AT100, GFAP, synaptophysin, and PSD95 immunoreactivity densities were determined using a multithreshold plug-in within NIH ImageJ (Figueiredo et al., 2013). Immunostaining was performed in parallel in slides from all animals and the same acquisition parameters were used when slides were analyzed. Cells positive for CP13 and IBA-1 were manually counted according the immunoreactivity in 20-30 images from each region-of-interest for each animal, acquired with the same parameters. For synaptic puncta analyses, a total of 15-20 images per experimental condition were acquired. PSD-95 (red) and synaptophysin (green) immunofluorescence was analyzed and quantified using the Puncta Analyzer plugin in NIH ImageJ as previously described (Christopherson et al., 2005). Analyses were performed in blinded fashion.

Electron microscopy of synapses. For synapses ultrastructural analysis, tissue samples from the prefrontal cortex of macaque's brains were fixed (paraformaldehyde $4 \%$ ) and postfixed by immersion in $1 \%$ osmium tetroxide in cacodylate buffer with $0.8 \%$ potassium ferrocyanide for $3 \mathrm{~h}$ at room temperature. The samples were washed three times with $0.1 \mathrm{M}$ phosphate buffer, $\mathrm{pH} 7.4$, and dehydrated with a graded acetone series. Uranyl acetate (1\%) was added to the $70 \%$ ethanol (35 min immersion) to improve contrast in the electron microscope. The sections were then embedded in POLYBED 812 resin (EMS) and polymerized for $48 \mathrm{~h}$ at $60^{\circ} \mathrm{C}$. The ultrathin sections were cut with a RMC ultramicrotome, collected on copper grids and stained with uranyl acetate and lead citrate and observed in a JEOL transmission EM (JEOL 1011). Images were taken at 30,000× magni- fication. A total of fifty images were acquired per animal/experimental condition ( $n=3$ sham-operated macaques; $n=4 \mathrm{~A} \beta \mathrm{O}$-injected macaques). Synaptic profiles were identified by the presence of the postsynaptic density and presynaptic vesicles. Electron microscopy analysis was performed in blinded fashion.

Electron microscopy analyses. Briefly, images were acquired randomly using a JEOL transmission EM (JEOL 1011) with a digitalizing image system (Gatan). Synapses were quantified in the neuropil (i.e., avoiding the neuronal and glial somata and blood vessels). All synapses were counted in each electron micrograph, which represented $\sim 7.4 \mu \mathrm{m}^{2}$ of tissue (total $\sim 370 \mu \mathrm{m}^{2}$ per animal). Units presenting synaptic vesicles in the presynaptic element and presynaptic and postsynaptic membrane specializations visible with or without synaptic cleft evident were counted. Synaptic profiles touching the edge micrographs were not counted. The cross-sectional length of synaptic junctions was measured using Image analysis software (NIH).

Immunogold electron microscope. For postembedding immunogold electron microscopy fixed tissue were washed in phosphate buffer, $\mathrm{pH}$ 7.4, dehydrated through a graded ethanol series, embedded in LRWhite resin (Sigma-Aldrich) and polymerized at $50^{\circ} \mathrm{C}$, for $24 \mathrm{~h}$. Ultrathin sections were obtained on a RMC ultramicrotome and collected on nickel grids. All sections were blocked with PBS enriched with 1\% BSA and $0.5 \%$ powdered skim milk for $1 \mathrm{~h}$, and incubated in the following tau antibodies at the indicated dilutions: Alz-50 (1:100), MC1 (1:100), and PHF-1 (1:100), $12 \mathrm{~h}$ at room temperature. After being rinsed for $20 \mathrm{~min}$ in enriched PBS, the sections were incubated in the secondary antibody goat anti-mouse IgG conjugated to $10 \mathrm{~nm}$ gold particles (1:100, BBI Solutions, catalog \#EM.GFAF10). Sections were rinsed three times for 10 min each in PBS, and three times for 10 min each in distilled water. As a control for the specificity of immunolabeling, omission of the primary antibody from incubation solutions completely abolished immunostaining for the corresponding antigens (data not shown). The sections were stained with uranyl acetate and lead citrate before examination with a Jeol (JEM 101) transmission electron microscope. Images were taken at $30,000 \times$ magnification. Electron microscopy analysis was performed in blinded fashion.

Western blotting. Western immunoblot analysis of the macaques brains was performed as described previously (Nirmalan et al., 2009). Samples from superior frontal gyrus of macaques were homogenized in RIPA buffer containing protease and phosphatase inhibitor cocktails and heated at $105^{\circ} \mathrm{C}$ for $20 \mathrm{~min}$. Extracts were incubated on ice for $5 \mathrm{~min}$, centrifuged at $14,000 \times g$ for $30 \mathrm{~min}$ and the supernatant was collected. 
Protein concentration was determined using the enhanced BCA protein assay kit (Pierce). Samples $(40 \mu \mathrm{g}$ total protein/lane) were resolved on a $4-20 \%$ polyacrylamide gel with Tris/glycine/SDS buffer run at $125 \mathrm{~V}$ for $80 \mathrm{~min}$ at room temperature. For experiments with anti-Tau antibodies, gel was electroblotted onto Odyssey nitrocellulose membrane using 25 mmTris, $192 \mathrm{~mm}$ glycine, 20\% (v/v) methanol, $0.02 \%$ SDS, $\mathrm{pH} 8.3$, at $350 \mathrm{~mA}$ for $2 \mathrm{~h}$ at $4^{\circ} \mathrm{C}$. Membranes were blocked with Odyssey blocking solution in Tris-buffered saline containing Tween 20 (TBS-T; $0.1 \%$ Tween 20 in 20 mmTris- $\mathrm{HCl}, \mathrm{pH} 7.5,0.8 \% \mathrm{NaCl})$ for $1 \mathrm{~h}$ at room temperature. Primary antibodies (taupSer396, 1:100, Tau-5 and anti- $\beta$-actin, 1:5000) were diluted in blocking solution/TBS and incubated with the membranes for $2 \mathrm{~h}$ at room temperature. After incubation with infrared labeled secondary antibodies goat anti-mouse IRDye 800 or goat anti-rabbit IRDye 800 IgG $(\mathrm{H}+\mathrm{L} ; 1: 10,000$ in blocking buffer, Invitrogen $)$ for $60 \mathrm{~min}$, membranes were washed and scanned in Odyssey Infrared System (Li-Cor Bioscience).

Dot blot. Dot blot was performed as described previously (Gong et al., 2003). Frontal cortex from adult rat brain was homogenized in 20 volumes of lysis buffer (PBS, pH 7.4, 0.32 M sucrose, 50 mmHepes, $25 \mathrm{~mm} \mathrm{MgCl} 2,0.5 \mathrm{~mm}$ DTT, $200 \mu \mathrm{g} / \mathrm{ml}$ PMSF, $2 \mu \mathrm{g} / \mathrm{ml}$ pepstatin A, 4 $\mu \mathrm{g} / \mathrm{ml}$ leupeptin, $30 \mu \mathrm{g} / \mathrm{ml}$ benzamidine hydrochloride), and centrifuged at $1000 \times g$ for $10 \mathrm{~min}$. The pellet was resuspended in $10 \mathrm{vol}-$ umes of lysis buffer and centrifuged again. The combined supernatants were centrifuged at $100,000 \mathrm{~g}$ for $1 \mathrm{~h}$. The pellet was then homogenized in 10 volumes of PBS plus protease inhibitors and was centrifuged at $100,000 \times g$ for $1 \mathrm{~h}$. Protein concentration of the combined supernatants was determined. An aliquot of protein $(5 \mu \mathrm{g})$ was then concentrated to a volume of $100 \mu \mathrm{l}$ or less using a Centricon-10 concentrator. Samples $(1 \mu \mathrm{g})$ were spotted onto a nitrocellulose membrane. Blots were incubated overnight in Tris-buffered saline containing 5\% nonfat dry milk, washed with TBST, and incubated with $3 \%$ hydrogen peroxide in $20 \%$ methanol for $30 \mathrm{~min}$ to quench endogenous peroxidase. Unbound material was washed away with TBST and bound $\mathrm{A} \beta$ oligomers were labeled with anti-aA $\beta$ Os (1:250) followed by HRP-conjugated secondary antibody incubation, visualized with Supersignal West Femtochemiluminescent substrate and imaged on photographic film.

TUNEL assay. The TUNEL assay was performed using a Dead-End TUNEL kit (Promega) according to the manufacturer's protocol. Briefly, the tissue was digested for $7 \mathrm{~min}$ in proteinase $\mathrm{K}(20 \mu \mathrm{g} / \mathrm{ml}$, Thermo Scientific). The reaction was terminated with PBS and the tissue autofluorescence was quenched by incubation with $0.06 \%$ potassium permanganate for $10 \mathrm{~min}$ at room temperature. Sections were incubated in solution containing the nucleotide mix and the rTdT enzyme for $1 \mathrm{~h}$. Nuclei were stained with DAPI for $5 \mathrm{~min}$. Treatment with DNase I $(10 \mathrm{U} / \mathrm{ml})$ was performed for positive control. Slices were mounted with Prolong Gold Antifade and imaged on a Zeiss Axio Observer $\mathrm{Z} 1$ microscope. Five to 10 images were acquired for each slice. Apoptotic cells were counted when double-stained for TUNEL and DAPI.

Statistical analyses. Data are represented as averages \pm SEM. All statistical analyses were performed with GraphPadPrism. The $p$ values were obtained by a two-tail Student's $t$ test comparing control and $\mathrm{A} \beta \mathrm{O}-$ injected groups. Analysis of synaptic numbers was performed with a one-tail Student's $t$ test between groups. A $p$ value of $<0.05$ was considered significant.

\section{Results}

$\mathrm{A} \beta \mathrm{O}$ s diffuse and accumulate in neurons in the frontal cortex of rats and macaques

Our approach consisted of injecting $\mathrm{A} \beta \mathrm{O}$ s into the lateral ventricle of adult cynomolgus brains many years before ADlike features develop naturally in this species, as spontaneous accumulation of $\mathrm{A} \beta$-positive plaques in cynomolgus macaques can only be detected in those older than 20 years (Podlisny et al., 1991; Oikawa et al., 2010). A $\beta$ Os were freshly prepared before each intracerebroventricular injection and the preparations were routinely characterized by size exclusion chromatography and Western blots (data not shown), revealing a mixture of oligomers ranging from dimers, trimers, and tetramers to larger oligomers (Chromy et al., 2003; De Felice et al., 2007, 2008; Sebollela et al., 2012; Figueiredo et al., 2013; see Materials and Methods for details). A $\beta$ Os were initially injected in rats (Fig. $1 A$ ) and were detected in the frontal cortex by dot blot analysis of cortical homogenates using the oligomer-selective NU4 antibody that does not recognize monomers (Lambert et al., 2007; Fig. 1B). In fact, $\mathrm{A} \beta \mathrm{O}$ s diffused into the brain parenchyma and were abundantly detected in the frontal cortex using NU4 (Lambert et al., 2007; 
A Frontal cortex

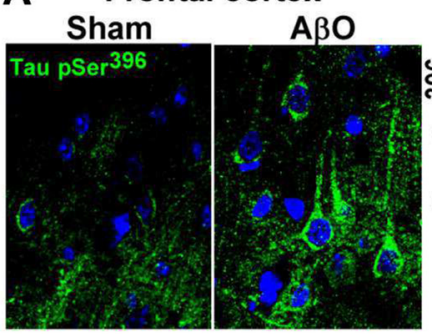

Dentate gyrus

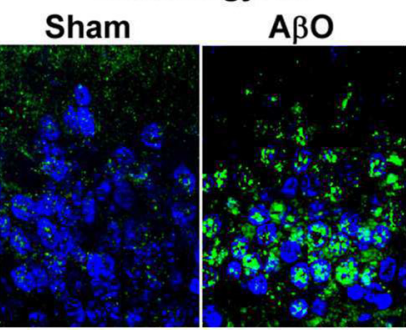

Amygdala

Sham

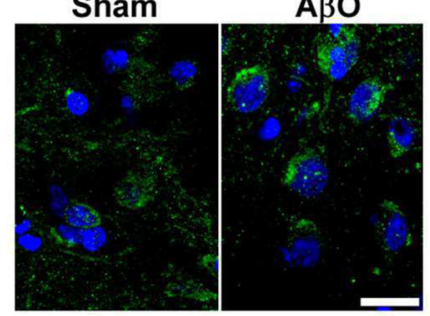

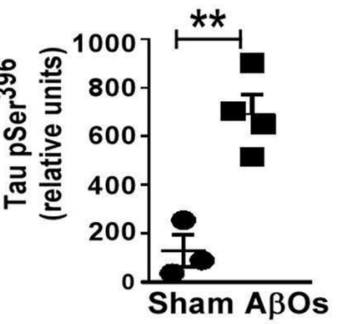
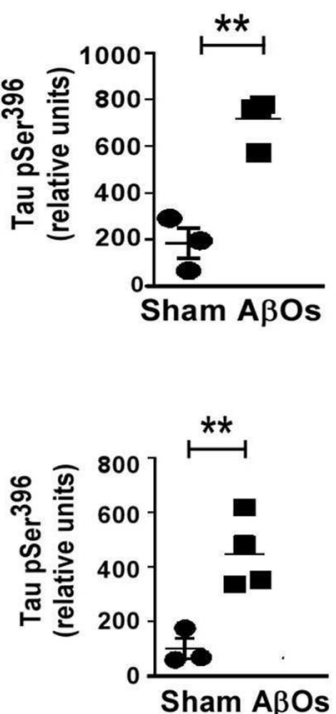

B Vehicle
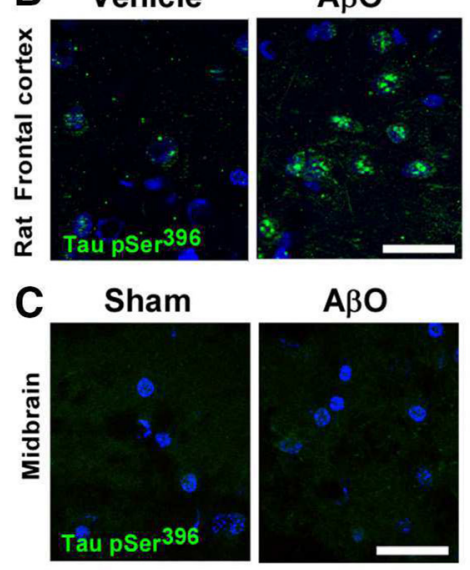

D Tau pSer 396

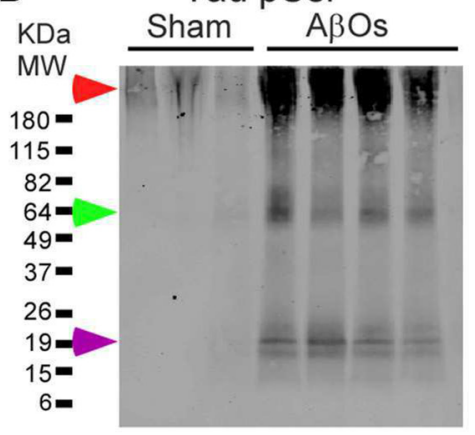

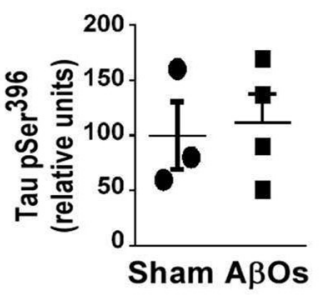

Tau-5

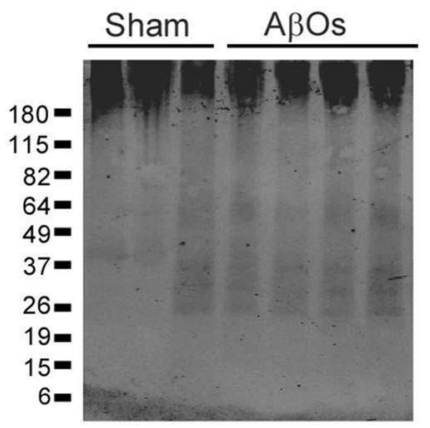

Figure 5. A $\beta 0$ s trigger tau phosphorylation in the rat and macaque brains. $A$, Representative micrographs showing tau-pSer ${ }^{396}$ immunofluorescence (green) and DAPl in the frontal cortex, dentate gyrus of the hippocampus and amygdalar complex in a sham-operated macaque and in a macaque that received intracerebroventricular injections of A $\beta 0$ s. Scale bar, $25 \mu \mathrm{m}$. Graphs show quantification of tau-pSer ${ }^{396}$ optical densities using DAB immunostaining (see Material and Methods) of frontal cortex, dentate gyrus, and amygdalar complex. $\boldsymbol{B}$, Representative micrographs of tau-pSer ${ }^{396}$ (green) immunofluorescence in the frontal cortex of rats that received intracerebroventricular injection of vehicle or $A \beta 0 \mathrm{~s}$ ( $n=4 / \mathrm{group}$ ). Scale bar, $50 \mu \mathrm{m}$. C, Representative micrographs of the midbrain of a sham-operated macaque and a macaque that received $\mathrm{A} \beta 0$ injections showing tau-pSer ${ }^{396}$ immunofluorescence. Scale bar, $50 \mu \mathrm{m}$. Quantification of tau-pSer ${ }^{396}$ densities using DAB immunostaining. Symbols represent the average values for each macaque. All error bars are $\pm S E M ;{ }^{* *} p<0.01$, Student's $t$ test. $D$, Western blot probed with anti-tau pSer ${ }^{396}$ revealed enhanced tau phosphorylation $(\sim 64 \mathrm{kDa})$ in all $\mathrm{A} \beta 30$-injected macaques compared with control macaque brains (green arrow); the presence of high molecular mass phospho-tau-reactive bands $(>150 \mathrm{kDa})$ in brain extracts from the frontal cortex of $A \beta 0$-injected macaques (red arrow). In addition, two low molecular mass phosphorylated tau fragments $(<20 \mathrm{kDa})$ were observed only in brain extracts from A $\beta 0$-injected macaques (purple arrow). A similar labeling profile between control and $A \beta 0$-injected macaques was observed when the same membrane was probed with the anti-Tau 5 antibody.

$n=13$; Fig. $1 C-E$ ). As expected, the frontal cortex of control rats that received injections of vehicle did not present any oligomer immunoreactivity $(n=13$; Fig. $1 E, F)$. A $\beta O$ s accumulated frequently in neurons, however, scattered glial cells were also observed presenting NU4 labeling (Fig. 1F,G). Thioflavin-Spositive fibrillar amyloid deposits were not detected in the brains of rats that received intracerebroventricular oligomer injections for 5 weeks (Fig. $1 H$ ), whereas such deposits were abundantly detected by thioflavin-S (Fig. 1I) and by the NU4 antibody (Fig. $1 J$ ) in the APPSwe,PS1 $\triangle \mathrm{E} 9$ a transgenic mouse model of AD.

We next injected $A \beta O$ s into the lateral ventricle of four cynomolgus macaques, whereas other three animals served as shamoperated controls (Fig. 2A). The amount of A $\beta O$ s successfully injected in each macaque was estimated and is plotted in Figure $2 B$ (see Materials and Methods for details). Similar to the results obtained in rats, $\mathrm{A} \beta \mathrm{O}$ s were found surrounding neuronal cell bodies and proximal cellular processes in the macaque frontal cortex and other cerebral regions (see below), whereas the controls presented no labeling (Fig. 2C). Comparable to what we observed in rats, $\mathrm{A} \beta \mathrm{O}$ s distributed throughout neocortical layers in macaques (Fig. 2D), accumulated in neurons. However, we noted that scattered glial cells presented NU4 labeling (Fig. 2E). As in rats, no fibrillar $\mathrm{A} \beta$ deposits were detected in the brains of macaques that received intracerebroventricular $\mathrm{A} \beta \mathrm{O}$ injections for 3 weeks (data not shown). We next examined highermagnification images of the frontal cortex of $\mathrm{A} \beta \mathrm{O}$-injected macaques immunolabeled with $\mathrm{NU}-4$, as well as with the anti-A $\beta$ antibodies $6 \mathrm{E} 10$ and $4 \mathrm{G} 8$. As shown in Figure $2 F$, similar patterns of labeling were observed using the anti-oligomer antibody (NU4) and the anti-A $\beta$ antibodies. The three antibodies revealed the presence of surface and intracellular $A \beta$ in cells, while no extracellular aggregates were detected throughout the macaque brains. However, only the anti-oligomer NU4 (an antibody that does not recognize $\mathrm{A} \beta$ monomers), as shown in Figure $2 F$, allowed us to clearly differentiate $\mathrm{A} \beta \mathrm{O}$ s labeling in sham-operated controls and $\mathrm{A} \beta \mathrm{O}$-injected macaques.

$\mathrm{A} \beta \mathrm{O}$ s accumulate in distinct areas in the macaque and rat brains

To determine whether there was any regional specificity in brain accumulation of oligomers, we analyzed the distribution of $\mathrm{A} \beta \mathrm{O}$ immunoreactivity in 11 different areas in the macaque brain (Fig. $3 A$; Table 1 , top). Results showed that $\mathrm{A} \beta \mathrm{O}$ s distributed and accumulated in specific brain areas. $\mathrm{A} \beta \mathrm{O}$-positive neurons were abundantly detected in the entorhinal cortex, hippocampus (dentate gyrus), striatum, and amygdala. The thalamus exhibited 
A

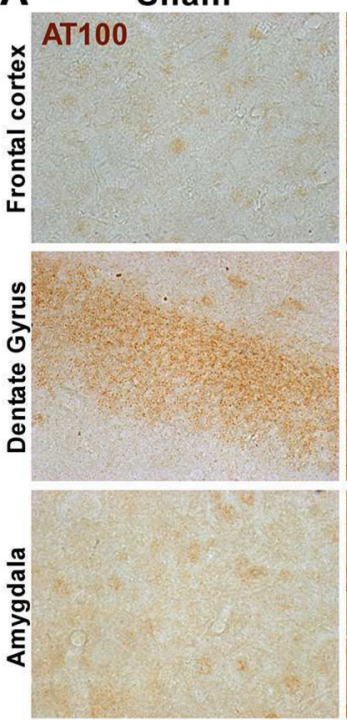

$A \beta O$
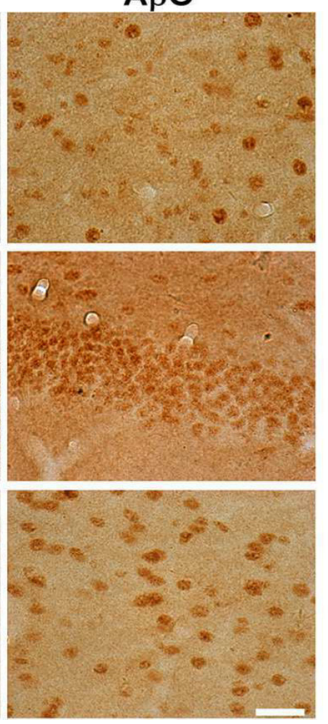

B
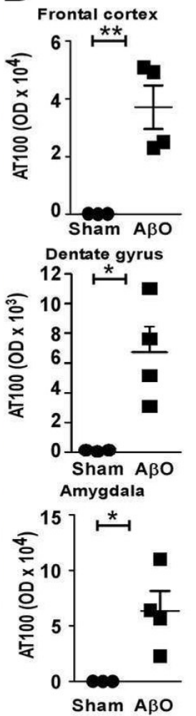
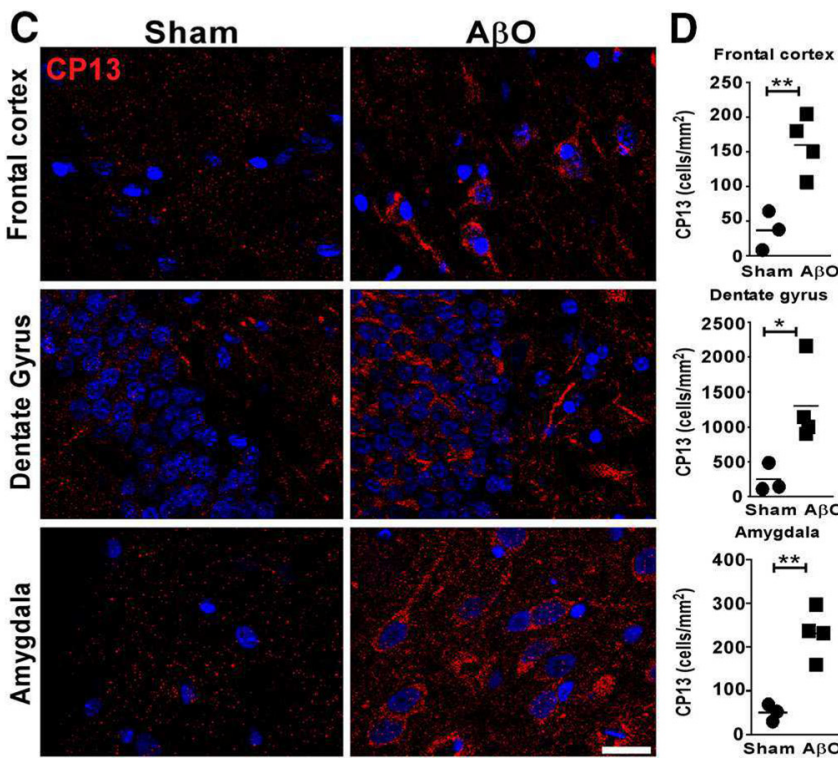

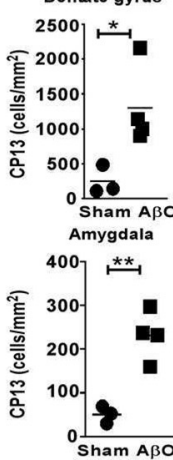

Figure 6. Detection of neurofibrillary tangles markers in the brains of $A \beta 0$-injected macaques. $A$, Representative micrographs showing AT100 immunostaining (phospho-tau at Ser212 and Thr214) in the frontal cortex, dentate gyrus and amygdalar complex from one sham-operated macaque and one A $\beta 0$-injected macaque. Scale bar, $50 \mu \mathrm{m}$. $\boldsymbol{B}, \mathbf{Q}$ uantification of AT100 optical densities using DAB immunostaining in the frontal cortex, dentate gyrus, and amygdalar complex. $C$, Representative micrographs showing CP13 immunofluorescence in the frontal cortex, dentate gyrus, and amygdalar complex from one sham-operated macaque and one A $\beta 0$-injected macaque. Scale bar, $50 \mu \mathrm{m}$. $D, 0$ uantification of CP13 positive cells in the frontal cortex, dentate gyrus, and amygdala. Symbols represent the average values for each macaque $(n=3$ sham; $n=4 \mathrm{~A} \beta 0)$. All error bars are \pm SEM; ${ }^{*} p<0.05,{ }^{* *} p<0.01$, Student's $t$ test. 0D, Optical density.

some labeling, and markedly fewer $\mathrm{A} \beta \mathrm{O}$-positive neurons were found in the midbrain or cerebellum (Fig. $3 B, C$ ). Parallel analysis in $\mathrm{A} \beta \mathrm{O}$-injected rats (Fig. $4 A$; Table 1 , bottom) showed a similar regional heterogeneity in oligomer distribution, although there were some differences in the percentages of detected cells in certain brain areas when compared with macaques (Fig. 4B). Interestingly, the pattern of $\mathrm{A} \beta \mathrm{O}$ labeling across the neuraxis in macaques was similar to that described for $\mathrm{A} \beta$ in $\mathrm{AD}$ patients (Thal et al., 2008).

\section{$\mathrm{A} \beta \mathrm{O}$ s trigger tau phosphorylation and tangle formation in macaque brains}

$\mathrm{A} \beta \mathrm{O}$ s have been shown to trigger abnormal tau phosphorylation in cultured neurons (De Felice et al., 2008; Jin et al., 2011). We next aimed to determine whether $\mathrm{A} \beta \mathrm{O}$ s triggered $\mathrm{AD}$-like tau phosphorylation in the macaque brain. When injected intracerebroventriculary, $\mathrm{A} \beta \mathrm{O}$ s induced tau hyperphosphorylation at serine residue 396, an AD-specific epitope (Bramblett et al., 1993), in the frontal cortex, dentate gyrus of hippocampus and amygdala (Fig. $5 A$ ), all regions in which $\mathrm{A} \beta \mathrm{O}$ s preferentially accumulated (Fig. 3). A similar increase in phospho-tau levels was detected in the frontal cortex of rats that received $\mathrm{A} \beta \mathrm{O}$-injections (Fig. $5 B$ ) In contrast, phospho-tau levels were not altered in the midbrain (Fig. $5 C$ ), a region that did not accumulate $\mathrm{A} \beta \mathrm{Os}$ (Fig. 3).

We next performed phospho-tau immunoblots of brain extracts (Van Hoesen et al., 2000) from all A $\beta O$-injected and control macaques. In Figure 5D, Western blots clearly revealed enhanced tau phosphorylation $(\sim 64 \mathrm{kDa})$ in the four $\mathrm{A} \beta \mathrm{O}$ injected macaques when compared with sham-operated control macaques (green arrow). We further noted the presence of high molecular mass phospho-tau-reactive bands $(>180 \mathrm{kDa})$ in brain extracts from the frontal cortex of $\mathrm{A} \beta \mathrm{O}$-injected macaques (Fig. 5D, red arrow). Such aggregates may correspond to tau oligomers, recently reported to be present in Alzheimer's disease brain extracts (Patterson et al., 2011; Lasagna-Reeves et al., 2012; Tai et al., 2012; Perez-Nievas et al., 2013). In addition, two low molecular mass $(<20 \mathrm{kDa})$ phosphorylated tau fragments were observed only in brain extracts from $\mathrm{A} \beta \mathrm{O}$-injected macaques (Fig. 5D, purple arrow). Truncated small tau fragments (10 and $12 \mathrm{kDa}$ ) have been early described to be present in neurofibrillary tangles in the brains of Alzheimer's patients (Wischik et al., 1988; Novak et al., 1993; Novák, 1994; Zilka et al., 2006). Although a toxic role of truncated tau fragments has been proposed, this issued remains to be better elucidated. When the same membrane was probed with the anti-Tau 5 antibody (which recognizes both phosphorylated and nonphosphorylated isoforms of tau), we observed similar labeling profiles in brain extracts from controls and $\mathrm{A} \beta \mathrm{O}$-injected macaques (Fig. $5 D$ ). This result indicates that $\mathrm{A} \beta \mathrm{O}$ injections affected phosphorylated tau levels in the macaque brain.

We next aimed to evaluate abnormal tau phosphorylation in our model using different tau antibodies. We initially investigated the levels of paired helical filaments (PHFs) reactive to the AT100, which recognizes tau phosphorylated at serine residue 212 and threonine residue 214 (Martinez-Coria et al., 2010), in the frontal cortex, dentate gyrus and amygdala of macaques and increases in AT100 levels in $\mathrm{A} \beta \mathrm{O}$-injected macaques were found in all three regions (Fig. $6 A, B)$. Further tests using the CP13 antibody, which recognizes tau phosphorylated at serine residue 202 (Espinoza et al., 2008), also indicated that intracerebroventricular injections of $\mathrm{A} \beta \mathrm{O}$ s led to a significant increase in the number of CP13-positive neurons (Fig. 6C,D). Abundant CP13-positive neurons were further found in the CA1, CA2, CA3, and subiculum (data not shown). AT100- and CP13-positive neurons represent early stage markers of tau pathology, respectively. In conclusion, tau was found to be altered and phosphorylated at multiple residues as a result of the impact of $A \beta O$ in the macaque brain.

We performed additional experiments using thioflavin-S staining and specific antibodies to detect the presence of neu- 

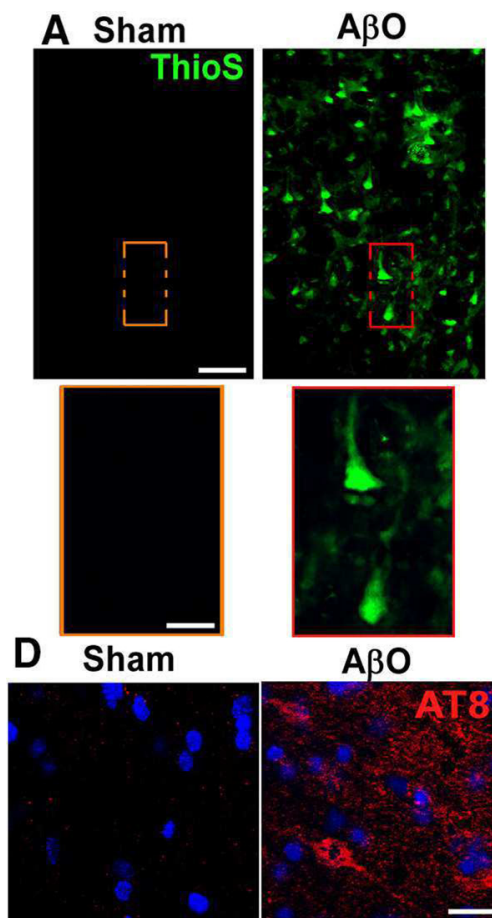

$\mathrm{A} \beta \mathrm{O}$

\section{$\mathbf{F}$}

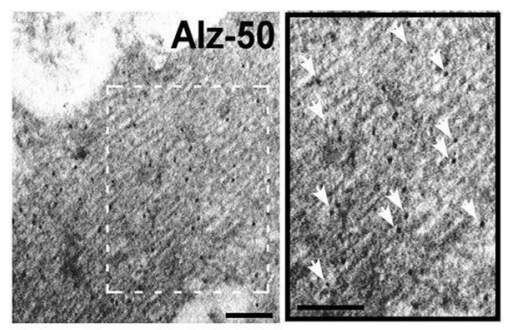

B

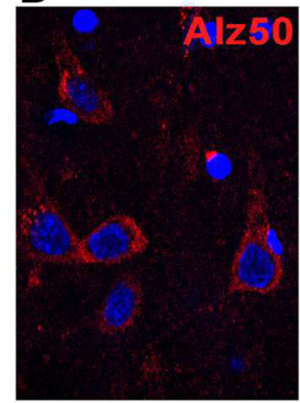

C

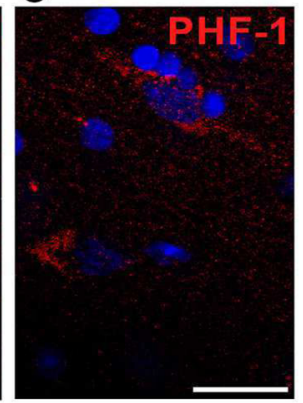

E

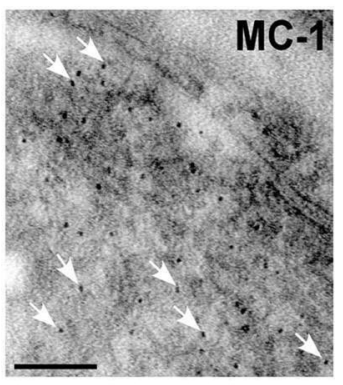

G

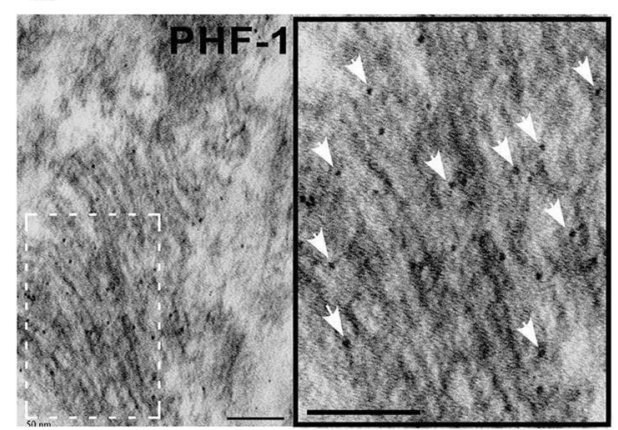

Figure 7. $A \beta 0$ s induce neurofibrillary tangle formation in the brains of macaques. $A$, Thioflavin- $S$ staining in the frontal cortex of macaques indicates neurofibrillary tangles formation in neurons of the frontal cortex. Scale bar, $100 \mu \mathrm{m}$. Optical zoom images of selected thioflavin S-positive neurons in $A \beta 0$ macaque (red dashed rectangles), no thioflavin-S staining was detected in the sham-operated macaques. Scale bar, $5 \mu \mathrm{m}$. Representative immunofluorescence of Alz50 (B), PHF-1 $(\boldsymbol{C})$, and AT8 $(\boldsymbol{D})$ reveals the presence of tangles in the frontal cortex of an $A \beta 0$-injected macaque. Immunogold electron microscopy in the frontal cortex of a $A \beta 0$-injected macaque using conformational antibodies $\mathrm{MC}-1(\boldsymbol{E})$, Alz50 $(\boldsymbol{F})$, and PHF-1 for phospho-tau Ser306 and Ser404 (G). Scale bar, $50 \mathrm{~nm}$. The ultrastructure in high-magnification reveals straight tau filaments that resemble neurofibrillary tangles described in transgenic mice (Ramsden et al., 2005; Oddo et al., 2007) and AD brain (Thorpe et al., 2001; Rissman et al., 2004). Arrowheads point to MC-1, Alz-50, and PHF-1 labeling. Scale bar, $50 \mathrm{~nm}$. Thio S, Thioflavin S.

rofibrillary tangles. Numerous thioflavin-S-positive neurons were found in the neocortex of macaques that received $\mathrm{A} \beta \mathrm{O}$ injections, while no staining was detected in the shamoperated macaques (Fig. 7A). The pattern of thioflavin-S labeling throughout the macaque cortex resembled the pattern of tangles described in AD (Van Hoesen et al., 2000; Murray et al., 2011). Extensive analysis of the brains of rats receiving intracerebroventricular injections of $\mathrm{A} \beta \mathrm{O}$ failed to detect thioflavin-S-positive tangles $(n=13$, data not shown), even though phospho-tau levels were increased in the brains of those rats (Fig. 5B). In addition, Alz50- and PHF-1-positive neurons were only observed in the frontal cortex of macaques that received intracerebroventricular injections of $\mathrm{A} \beta \mathrm{O}$ s (Fig. $7 \mathrm{~B}, \mathrm{C})$. Alz50 is a conformational antibody described to recognize paired helicoidal filament tau (Wolozin et al., 1986) and PHF-1 is described to recognize tau phosphorylation at serine residues 396 and 404 (Greenberg and Davies, 1990). AT8-positive (Merrick et al., 1996) neurons were further ob- served in the frontal cortex of macaques that received intracerebroventricular injections of $\mathrm{A} \beta \mathrm{O}$ s (Fig. $7 D$ ).

Next, we aimed to determine whether neurofibrillary tangles were present in the brains of macaques that received intracerebroventricular injections of $\mathrm{A} \beta \mathrm{O}$, and to investigate tangle pathology from an ultrastructural perspective. Immunogold electron microscopy was performed using MC-1 reported to detect early conformational changes in tangle formation (Jicha et al., 1997; Rissman et al., 2004), Alz50, and PHF1 antibodies. Antibody-conjugated gold particles were found in association with tangle-like structures within neuronal soma in the frontal cortex of $\mathrm{A} \beta \mathrm{O}$ injected macaques (Fig. $7 E-G$ ), whereas no tangle-like structures were observed in control macaques (data not shown). This is in accordance with previous studies reporting that neurofibrillary tangle pathology is very difficult to detect in macaques $<30$ years of age (Oikawa et al., 2010; Finch and Austad, 2012; Heuer et al., 2012). It is interesting to note that the ultrastructure of tangles we observed is similar to tangle-like structures previously shown in $\mathrm{AD}$ brains and in transgenic mice (Rissman et al., 2004; Ramsden et al., 2005; Oddo et al., 2007).

\section{A $\beta$ os induce astrocyte and microglial activation}

Reactive gliosis, including astrocyte and microglial activation detected by increased glial fibrillary acidic protein (GFAP) and microglial levels, are other important features of AD neuropathology (Mattson, 2004; Serrano-Pozo et al., 2011). We recently showed that $A \beta O$ s trigger astrocyte and microglial activation in the brains of mice (Ledo et al., 2013) and activation of a proinflammation pathway was found to be linked to memory loss and impaired insulin signaling in $\mathrm{AD}$ (Bomfim et al., 2012; Lourenco et al., 2013). Therefore, we next aimed to determine whether $\mathrm{A} \beta \mathrm{O}$ s induce astrocyte and microglial activation in our model. Sections from the frontal cortex, hippocampus and amygdala of controls or $\mathrm{A} \beta \mathrm{O}$-injected macaques were immunostained for the presence of astrocytes (using anti-GFAP antibody and microglia (using anti-IBA-1 antibody). Compared with sham-operated animals, $\mathrm{A} \beta \mathrm{O}$-injected macaques showed markedly increased immunoreactivity for GFAP (Fig. 8) and IBA-1 (Fig. 9) in the analyzed areas. This suggests the presence of astrocyte/microglial-mediated inflammatory processes triggered by $\mathrm{A} \beta \mathrm{O}$ in macaques.

\section{Injections of $\mathrm{A} \beta \mathrm{O}$ s into the macaque brain do not lead to apoptosis}

We next investigated TUNEL in our model of $\mathrm{A} \beta \mathrm{O}$-injections, to examine DNA fragmentation in cells undergoing apoptosis. In 
sections from sham-operated macaques treated with DNase I as a positive control, several TUNEL-positive cells were observed (Fig. 10A). However, in both sham-operated and $\mathrm{A} \beta \mathrm{O}$-injected macaques, very few cells were detected to present TUNEL in the frontal cortex (Fig. $10 A, B)$ and amygdala (Fig. 10C). In the hippocampus, no TUNEL staining was detected in all seven macaques (data not shown). Overall, our results indicate that $\mathrm{A} \beta \mathrm{O}$-injected macaques do not present increase in apoptosis when compared with the sham-operated macaques, at least for the duration they were followed in the present study.

A $\beta$ Os trigger synapse loss in macaques Synapse loss is the best pathological correlate of the degree of dementia in $\mathrm{AD}$ (Masliah et al., 2001; Scheff et al., 2007). To determine whether synapses were impacted by $\mathrm{A} \beta \mathrm{O}$ in vivo, we examined levels of the presynaptic and postsynaptic markers synaptophysin and postsynaptic density-95 (Cook et al., 2012), respectively. Compared with the sham-operated animals, macaques that received intracerebroventricular injections of $\mathrm{A} \beta \mathrm{O}$ s exhibited dramatic reductions in levels of both synaptophysin (Fig. 11A) and PSD-95 (Fig. 11B) in the frontal cortex, hippocampus and amygdala, indicating that oligomers induce damage to both presynaptic and postsynaptic proteins. We further analyzed synaptic puncta number in immunohistology. Results indicate that $\mathrm{A} \beta \mathrm{O}$-injected macaques exhibit decreased numbers of puncta corresponding to presynaptic synaptophysin (Fig. 11C) and postsynaptic PSD-95 (Fig. $11 D)$ immunoreactivities in the frontal cortex. We next performed electron microscopy analysis to assess synapse density ultrastructurally. Synaptic profiles were identified by the presence of the postsynaptic density and presynaptic vesicles. We found that synapse number was decreased by $15 \%$ in $\mathrm{A} \beta \mathrm{O}$-injected macaques, compared with controls (Fig. 11E).

\section{Discussion}

Here, we demonstrate that intracerebroventricular-injected $\mathrm{A} \beta \mathrm{O}$ s diffuse into the brain parenchyma and accumulate in memory-related areas in the nonhuman primate brain, causing tau and synaptic pathology, as well as astrocyte and microglial activation. By injecting $\mathrm{A} \beta \mathrm{O}$ s into the ventriculum of adult macaques, we developed a nonhuman primate model that accurately recapitulates central pathological facets of human AD. Human and macaque brains share considerable simi-
A
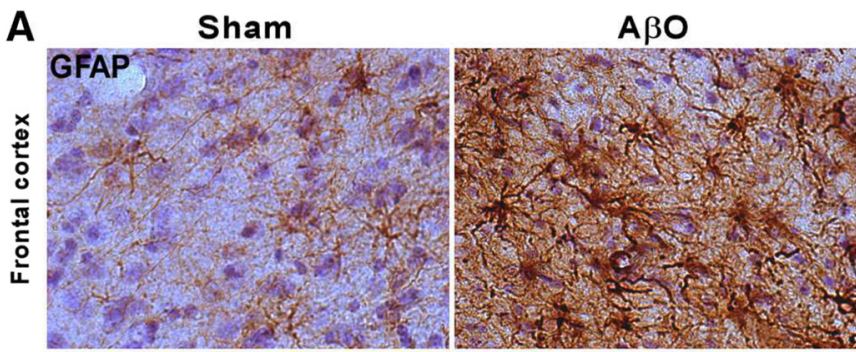

B
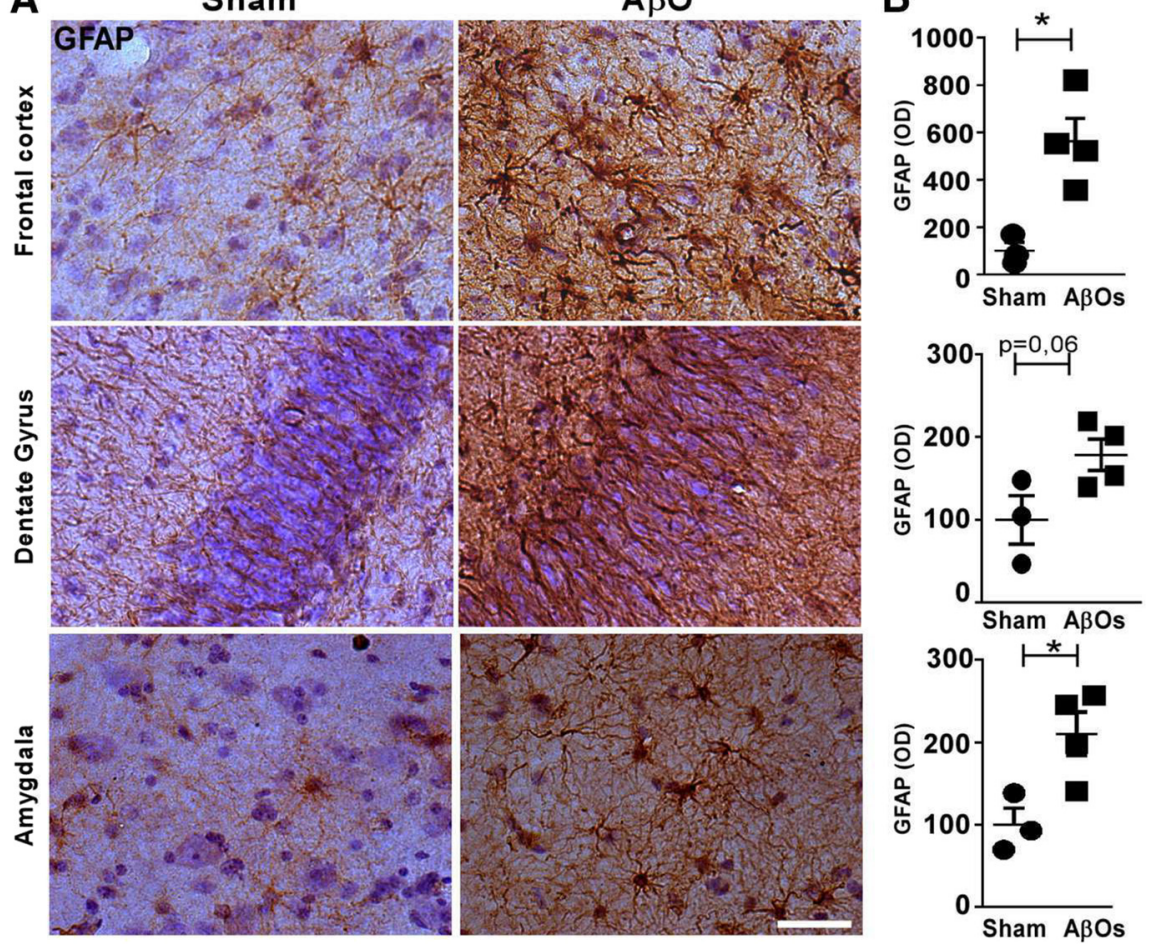

Figure 8. Amyloid- $\beta$ oligomers induce astrocyte activation in the brains of macaques. $\boldsymbol{A}$, Representative micrographs showing GFAP immunostaining in the frontal cortex, dentate gyrus and amygdalar complex of a sham-operated macaque and an A $\beta 0$-injected macaque. Scale bar, $50 \mu \mathrm{m}$. B, Quantification of GFAP optical densities by DAB immunostaining. Symbols represent the average values for each macaque. All error bars are $\pm S E M ;{ }^{*} p<0.05$, Student's $t$ test. 0D, 0ptical density.

A
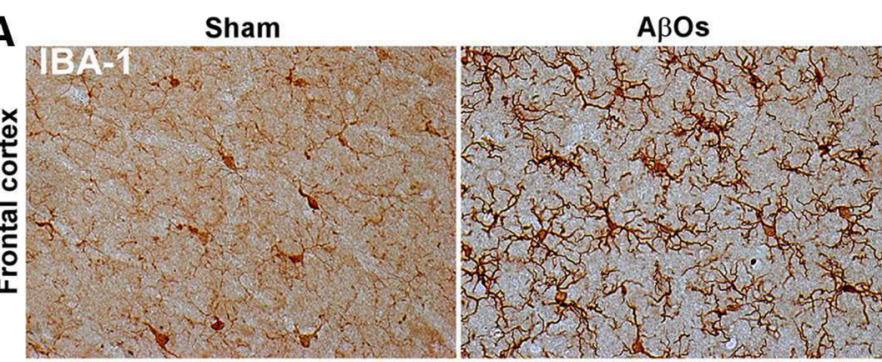

B
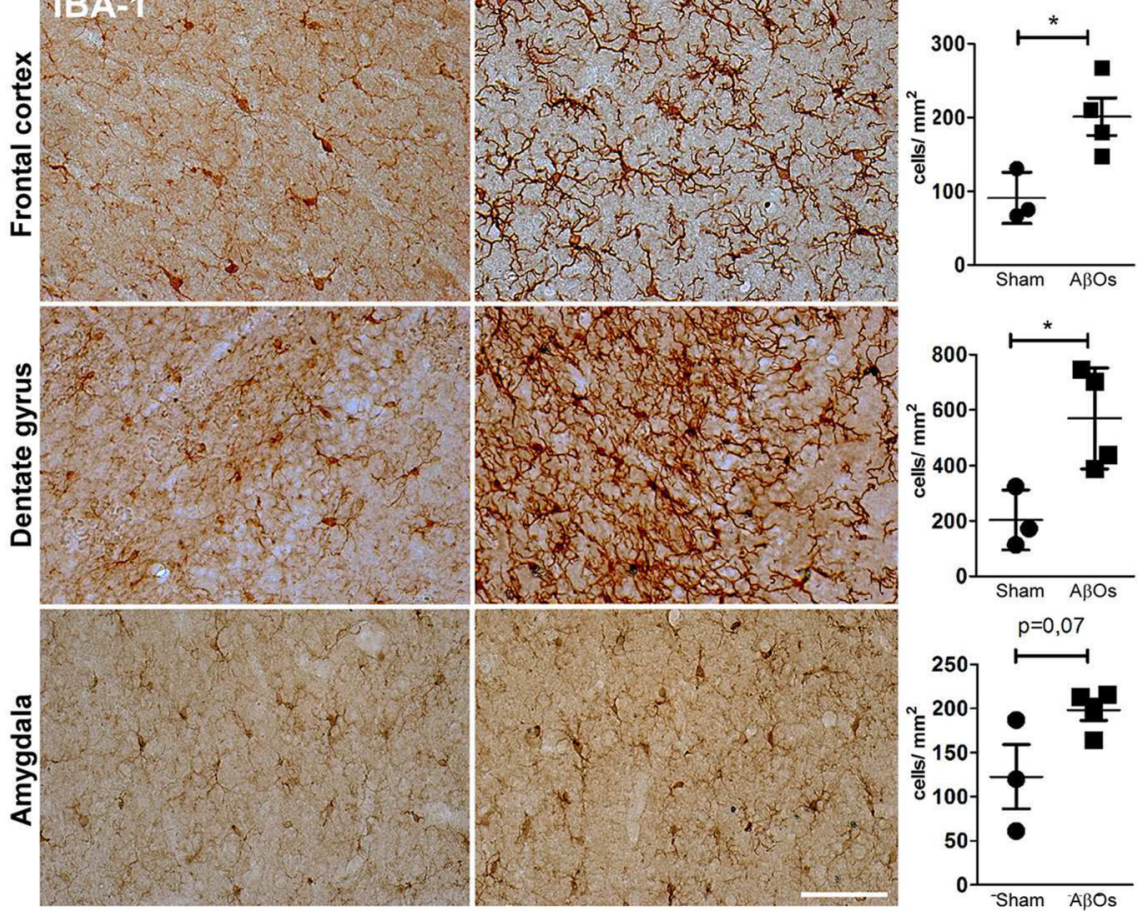

Figure 9. $A \beta 0$ s induce microglial activation in the brains of macaques. $\boldsymbol{A}$, Representative micrographs showing lba- 1 $D A B$ immunostaining in the frontal cortex, dentate gyrus, and amygdalar complex of a sham-operated macaque and an $A \beta 0$-injected macaque. Scale bar, $50 \mu \mathrm{m}$. B, Quantification of Iba-1 positive cells. Symbols represent the average values for each macaque. All error bars are \pm SEM; ${ }^{*} p<0.0$, Student's $t$ test. IBA-1, Ionized calcium-binding adapter molecule 1. 
A
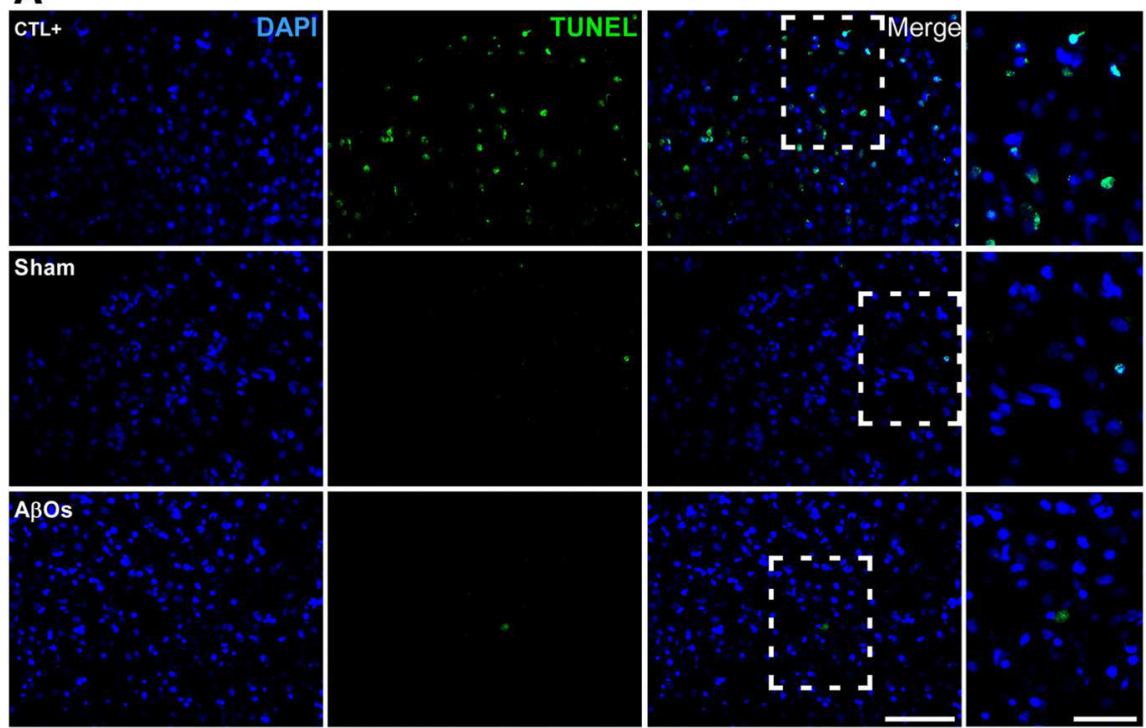

B

Frontal cortex

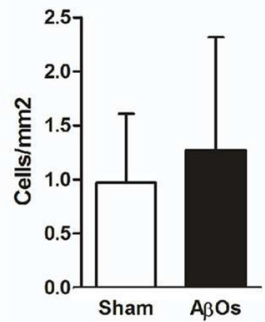

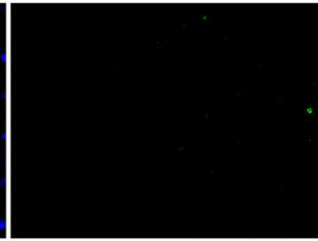
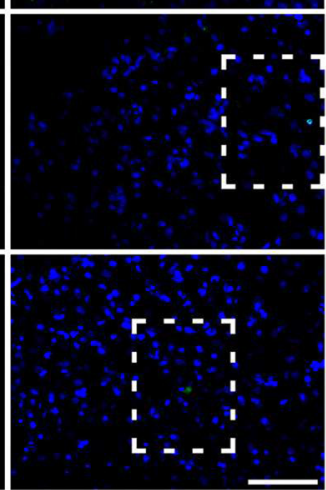

C

Amygdala

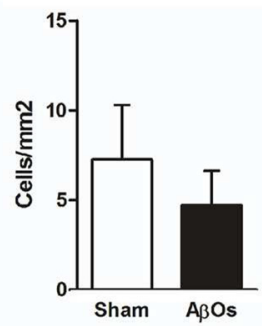

Figure 10. A $A 0$ s do not induce apoptosis in the brains of macaques. $\boldsymbol{A}$, Representative images of TUNEL staining in the frontal cortex of macaques; experimental conditions as indicated. DNase I was used as a positive control (see Materials and Methods). Scale bar, $100 \mu \mathrm{m}$. Optical zoom images of selected regions are also presented. Scale bar, $50 \mu \mathrm{m} . \boldsymbol{B}, \boldsymbol{C}$, Quantification of TUNEL-positive cells in the frontal cortex and amygdala in sham-operated macaques and $\mathrm{A} \beta 0$-injected macaques.

larities in terms of overall architecture and functional networks. Thus, generation of a nonhuman primate model to study the effects of $\mathrm{A} \beta \mathrm{O}$ s has the potential to greatly advance our understanding of mechanisms centrally implicated in $\mathrm{AD}$ pathogenesis and for therapeutic development effective in primate brains. We note that although $\mathrm{A} \beta \mathrm{O}$ injections produce pathology similar to $\mathrm{AD}$, the pathology observed has been induced acutely, whereas $\mathrm{AD}$ progresses over decades and, therefore, it is not identical to the nonhuman primate model. Nonetheless, such a model of AD may help bridge the gap between promising rodent research and the human disease condition and such model may be useful for testing therapeutic interventions for AD.

In $\mathrm{AD}$ brains, an imbalance between $\mathrm{A} \beta$ production and clearance is thought to cause accumulation of $\mathrm{A} \beta \mathrm{O}$. As $\mathrm{A} \beta \mathrm{O}$ s continue to accumulate in $\mathrm{AD}$ brains, larger aggregates tend to form and amyloid deposits start to build up. The spatiotemporal deposition of $A \beta$ in the $A D$ brain has been described as a progressive process (Thal et al., 2008). The neocortex is involved earlier than allocortical regions (e.g., entorhinal region, and hippocampus), which in turn show $\mathrm{A} \beta$ deposits before striatum and thalamus. Specific brainstem regions are subsequently involved and finally $\mathrm{A} \beta$ deposits are seen in the cerebellum (Thal et al., 2008; Grinberg et al., 2009; Braak et al., 2011). In accordance with the sequential involvement of brain regions in $\mathrm{AD}$, we found that $\mathrm{A} \beta \mathrm{O}$ s accumulated in the macaque brain in a region-specific manner, generating an $\mathrm{AD}$-like intermediary stage, with the neocortex, hippocampus, striatum and thalamus being affected by $\mathrm{A} \beta \mathrm{O}$ s (Fig. 3). The finding that brain regions associated with cognitive functions highly accumulate $\mathrm{A} \beta \mathrm{O}$ s provides a molecular basis for why early $\mathrm{AD}$ is primarily a disease of memory.

Intriguingly, $\mathrm{A} \beta \mathrm{O}$ s did not accumulate in periventricular regions near the injection site in the primate brain. The exact mechanism by which $\mathrm{A} \beta \mathrm{O}$ s accumulate in some brain regions, including regions located at a considerable distance from the ventricles, remains unknown. However, it likely depends on the presence of locally differentiated lipid membrane domains that combine particular proteins (and perhaps lipids) that act as $\mathrm{A} \beta \mathrm{O}$ receptors. For example, in hippocampal cultures, $\mathrm{A} \beta \mathrm{O}$ s bind only a neuronal subpopulation, whereas in cerebellar cultures there is virtually no binding (Gong et al., 2003). In synaptosomes, $\mathrm{A} \beta \mathrm{O}$ s bind to cortical but not cerebellar preparations (Lacor et al., 2007). Therefore, it is possible that neurons in areas that preferentially accumulate $\mathrm{A} \beta \mathrm{O}$ s in macaque brains present one or more surface proteins forming a receptor complex required for specific oligomer binding (Ferreira and Klein, 2011; Selkoe, 2011). In the human disease, we can speculate that $\mathrm{A} \beta \mathrm{O}$ s would initially accumulate in regions enriched with neurons presenting such a specific oligomer receptor complex, with progressive accumulation of $\mathrm{A} \beta \mathrm{O}$ s leading to formation of $\mathrm{A} \beta$ deposits in those regions. As disease progresses, oligomers diffuse and begin accumulating in additional regions also containing (albeit it in lower proportion) neurons with the appropriate receptor complex. Eventually, at later disease stages, oligomers may reach regions presenting low numbers of neurons expressing the receptor complex, such as the cerebellum.

We detected the presence of surface and intracellular $\mathrm{A} \beta$ in neurons, while no extracellular aggregates were detected throughout the $\mathrm{A} \beta \mathrm{O}$-injected macaque brains. Although $\mathrm{A} \beta$ has been classically described to deposit extracellularly, emerging evidence from transgenic mice and human patients indicates that this peptide can also accumulate intraneuronally and this may contribute to disease progression (Gouras et al., 2000; LaFerla et al., 2007) and onset of cognitive dysfunction. It is possible that prolonged injections of $\mathrm{A} \beta \mathrm{O}$ in macaques would give rise to the formation of amyloid deposits. Nevertheless, the absence of amyloid deposits in our model was crucial to establish that $\mathrm{A} \beta \mathrm{O}$, independent of the presence of fibrils, trigger tau phosphorylation, tangle formation, and synapse loss in the primate brain.

As recently pointed out, development of an animal model of $\mathrm{AD}$ that best approximates the human disease has been the goal of several groups and is an important concern in the AD field (Selkoe, 2011; LaFerla and Green, 2012). Major insights into the function of genes associated with $\mathrm{AD}$ and associated dementias came from studies using genetically modified animals (LaFerla and Green, 2012). In particular, however, there is an urgent need to develop animal models of $\mathrm{AD}$ that better correlates with the 
much more frequent sporadic forms of $\mathrm{AD}$. In sporadic, late-onset $\mathrm{AD}$, no gene mutations have been identified and the pathogenic trigger has not been explicitly identified but is increasingly believed to comprise soluble $\mathrm{A} \beta \mathrm{O}$ s (Hardy and Selkoe, 2002; Shankar et al., 2007; De Felice et al., 2008; Bomfim et al., 2012; Chabrier et al., 2012). A few alternative approaches have used nonhuman primates. Some studies have relied upon naturally occurring $\mathrm{A} \beta$ deposits in aged macaques (Podlisny et al., 1991; Oikawa et al., 2010; Toledano et al., 2014). However, due to the long lifespan of primates, such studies may take many years or decades to come to fruition. Other groups have performed intracerebral injections of fibrillar $\mathrm{A} \beta$, causing astroglial activation and neuronal loss closely associated with $\mathrm{A} \beta$ deposits (Geula et al., 1998; Leung et al., 2011). As mentioned previously, it is important to note that, except for the baboon (Goedert and Spillantini, 2006), primates seem to be resistant to the development of neurofibrillary tangle pathology unless they are older than 30 years of age (Schultz et al., 2000). It is thus important that we were able to reproduce key aspects of human $\mathrm{AD}$ pathology by performing a few intracerebroventricular injections of $\mathrm{A} \beta \mathrm{Os}$ $(\sim 100$ nmol total $A \beta)$ spaced over a 3 week period. We note that although we have used 9- and 16-year-old macaques, all the analyses performed throughout our work revealed very similar results with animals of different ages within each experimental group. Thus, variable ages used in our work did not seem to have played any noticeable role in the effects of $A \beta O$ s. Oligomers rapidly induced tau and synaptic pathology at specific brain areas, indicating that this model promptly and efficiently produces specific pathological hallmarks of $\mathrm{AD}$. This underscores the relevance of studying mechanisms germane to $\mathrm{AD}$ in macaques, as tangles are not found in rats receiving intracerebroventricular injections of $\mathrm{A} \beta \mathrm{O}$ s or generally not present in transgenic rodent models of $\mathrm{AD}$, unless they also carry a specific mutation in tau (Oddo et al., 2003b; Yoshiyama et al., 2007; Filipcik et al., 2012). Therefore, the continued improvement and progress to generate novel animal models are highly anticipated.

Development of successful strategies to prevent or treat $\mathrm{AD}$ depends critically on detailed knowledge of clinically relevant mechanisms recognized to be central to the disease process. Due to the close similarities between the human and macaque brains in terms of overall architecture and functional networks, the macaque model of $\mathrm{AD}$ described here holds considerable potential for allowing detailed molecular mapping of pathology onto functional networks and its correlations with clinical outcomes in a context that would be much more readily translated to the human disease than with currently available rodent models. In fact, a significant impediment to the development of safe and effective therapeutics for several diseases may lie in species differences between humans and animal models used in preclinical studies. Therapies that work in other animals (e.g., rodents) often do not
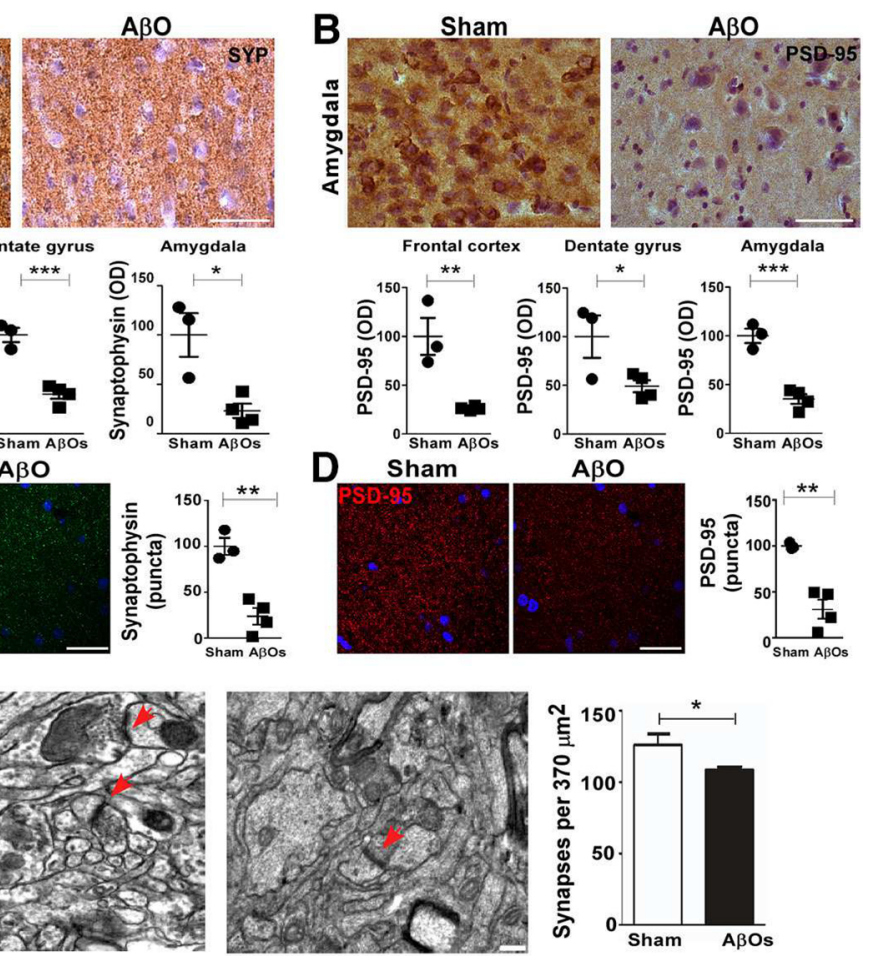

Figure 11. A $A 0$ s trigger synapse loss in macaques. $\boldsymbol{A}$, Representative micrographs showing synaptophysin immunotification of the total number of synapses. Graph represents mean \pm SEM $(n=3$ sham; $n=4 \mathrm{~A} \beta 0)$. All error bars are \pm SEM; ${ }^{*} p<0.05,{ }^{* *} p<0.01,{ }^{* * *} p<0.001$, Student's $t$ test.

translate to specific human disease conditions. For example, several candidate therapeutic agents have proven effective in rodent models of stroke, but all of them have failed to achieve their primary goal when brought forward to clinical trials (Philip et al., 2009). Indeed, considerable attention in the stroke field is now focused on studies of neuroprotective approaches in a novel macaque model (also using cynomolgus macaques) developed to more closely model the human disease (Fisher, 2009; Cook et al., 2012; Dolgin, 2012).We recently showed that an intracerebroventricular injection of $A \beta O$ s induces cognitive impairment and depressive-like behavior in mice (Figueiredo et al., 2013; Ledo et al., 2013). It is important to note that our approach does not rely on increased $\mathrm{A} \beta \mathrm{O}$ s being the root cause of sporadic $\mathrm{AD}$ in humans. We do propose that the presence of $\mathrm{A} \beta \mathrm{O}$ s is critical for the disease cascade and, therefore, that understanding and then reversing the effect of intracerebroventricular injection of $\mathrm{A} \beta \mathrm{O}$ in nonhuman primates is likely to lead to development of new $\mathrm{AD}$ therapies. We further note that studies aimed at evaluating the impact of $\mathrm{A} \beta \mathrm{O}$ s on cognition in nonhuman primates will be important to extend this from a model of AD pathology to a full behavioral model of AD.

In conclusion, our findings indicate that $\mathrm{A} \beta \mathrm{O}$ s diffuse into the brain parenchyma and accumulate in several brain regions, inducing astrocyte and microglial activation, synapse loss, abnormal tau phosphorylation and neurofibrillary tangle formation in some brain regions associated with cognitive functions and operant behavior. Development of a macaque model of $\mathrm{AD}$ that 
recapitulates key aspects of $\mathrm{AD}$ pathology by introducing $\mathrm{AD}$ specific neurotoxins may represent a major step forward toward understanding mechanisms of AD pathogenesis and toward developing effective disease-modifying therapies.

\section{References}

Bomfim TR, Forny-Germano L, Sathler LB, Brito-Moreira J, Houzel JC, Decker H, Silverman MA, Kazi H, Melo HM, McClean PL, Holscher C, Arnold SE, Talbot K, Klein WL, Munoz DP, Ferreira ST, De Felice FG (2012) An anti-diabetes agent protects the mouse brain from defective insulin signaling caused by Alzheimer's disease- associated Abeta oligomers. J Clin Invest 122:1339-1353. CrossRef Medline

Braak H, Braak E (1991) Neuropathological stageing of Alzheimer-related changes. Acta Neuropathol 82:239-259. CrossRef Medline

Braak H, Thal DR, Ghebremedhin E, Del Tredici K (2011) Stages of the pathologic process in Alzheimer disease: age categories from 1 to 100 years. J Neuropathol Exp Neurol 70:960-969. CrossRef Medline

Bramblett GT, Goedert M, Jakes R, Merrick SE, Trojanowski JQ, Lee VM (1993) Abnormal tau phosphorylation at Ser396 in Alzheimer's disease recapitulates development and contributes to reduced microtubule binding. Neuron 10:1089-1099. CrossRef Medline

Chabrier MA, Blurton-Jones M, Agazaryan AA, Nerhus JL, Martinez-Coria H, LaFerla FM (2012) Soluble abeta promotes wild-type tau pathology in vivo. J Neurosci 32:17345-17350. CrossRef Medline

Christopherson KS, Ullian EM, Stokes CC, Mullowney CE, Hell JW, Agah A, Lawler J, Mosher DF, Bornstein P, Barres BA (2005) Thrombospondins are astrocyte-secreted proteins that promote CNS synaptogenesis. Cell 120:421-433. CrossRef Medline

Chromy BA, Nowak RJ, Lambert MP, Viola KL, Chang L, Velasco PT, Jones BW, Fernandez SJ, Lacor PN, Horowitz P, Finch CE, Krafft GA, Klein WL (2003) Self-assembly of Abeta(1-42) into globular neurotoxins. Biochemistry 42:12749-12760. CrossRef Medline

Cohen RM, Rezai-Zadeh K, Weitz TM, Rentsendorj A, Gate D, Spivak I, Bholat Y, Vasilevko V, Glabe CG, Breunig JJ, Rakic P, Davtyan H, Agadjanyan MG, Kepe V, Barrio JR, Bannykh S, Szekely CA, Pechnick RN, Town T (2013) A transgenic Alzheimer rat with plaques, tau pathology, behavioral impairment, oligomeric abeta, and frank neuronal loss. J Neurosci 33:6245-6256. CrossRef Medline

Cook DJ, Teves L, Tymianski M (2012) Treatment of stroke with a PSD-95 inhibitor in the gyrencephalic primate brain. Nature 483:213-217. CrossRef Medline

Crist CF, Yamasaki DS, Komatsu H, Wurtz RH (1988) A grid system and a microsyringe for single cell recording. J Neurosci Methods 26:117-122. CrossRef Medline

DaRocha-Souto B, Scotton TC, Coma M, Serrano-Pozo A, Hashimoto T, Serenó L, Rodríguez M, Sánchez B, Hyman BT, Gómez-Isla T (2011) Brain oligomeric beta-amyloid but not total amyloid plaque burden correlates with neuronal loss and astrocyte inflammatory response in amyloid precursor protein/tau transgenic mice. J Neuropathol Exp Neurol 70:360-376. CrossRef Medline

De Felice FG, Velasco PT, Lambert MP, Viola K, Fernandez SJ, Ferreira ST, Klein WL (2007) $A \beta$ oligomers induce neuronal oxidative stress through an $N$-methyl-D-aspartate receptor-dependent mechanism that is blocked by the Alzheimer drug memantine. J Biol Chem 282:1159011601. CrossRef Medline

De Felice FG, Wu D, Lambert MP, Fernandez SJ, Velasco PT, Lacor PN, Bigio EH, Jerecic J, Acton PJ, Shughrue PJ, Chen-Dodson E, Kinney GG, Klein WL (2008) Alzheimer's disease-type neuronal tau hyperphosphorylation induced by A $\beta$ oligomers. Neurobiol Aging 29:1334-1347. CrossRef Medline

Dolgin E (2012) To serve and neuroprotect. Nat Med 18:1003-1006. CrossRef Medline

Espinoza M, de Silva R, Dickson DW, Davies P (2008) Differential incorporation of tau isoforms in Alzheimer's disease. J Alzheimers Dis 14:1-16. Medline

Ferreira ST, Klein WL (2011) The Abeta oligomer hypothesis for synapse failure and memory loss in Alzheimer's disease. Neurobiol Learn Mem 96:529-543. CrossRef Medline

Figueiredo CP, Clarke JR, Ledo JH, Ribeiro FC, Costa CV, Melo HM, MotaSales AP, Saraiva LM, Klein WL, Sebollela A, De Felice FG, Ferreira ST (2013) Memantine rescues transient cognitive impairment caused by high-molecular-weight a $\beta$ oligomers but not the persistent impairment induced by low-molecular-weight oligomers. J Neurosci 33:9626-9634. CrossRef Medline

Filipcik P, Zilka N, Bugos O, Kucerak J, Koson P, Novak P, Novak M (2012) First transgenic rat model developing progressive cortical neurofibrillary tangles. Neurobiol Aging 33:1448-1456. CrossRef Medline

Finch CE, Austad SN (2012) Primate aging in the mammalian scheme: the puzzle of extreme variation in brain aging. Age (Dordr) 34:1075-1091. CrossRef Medline

Fisher M (2009) Stroke/international stroke conference collaboration. Stroke 40:1947. CrossRef Medline

Geula C, Wu CK, Saroff D, Lorenzo A, Yuan M, Yankner BA (1998) Aging renders the brain vulnerable to amyloid beta-protein neurotoxicity. Nat Med 4:827-831. CrossRef Medline

Goedert M, Spillantini MG (2006) A century of Alzheimer's disease. Science 314:777-781. CrossRef Medline

Gong Y, Chang L, Viola KL, Lacor PN, Lambert MP, Finch CE, Krafft GA, Klein WL (2003) Alzheimer's disease-affected brain: presence of oligomeric A beta ligands (ADDLs) suggests a molecular basis for reversible memory loss. Proc Natl Acad Sci U S A 100:10417-10422. CrossRef Medline

Götz J, Ittner LM (2008) Animal models of Alzheimer's disease and frontotemporal dementia. Nat Rev Neurosci 9:532-544. CrossRef Medline

Gouras GK, Tsai J, Naslund J, Vincent B, Edgar M, Checler F, Greenfield JP, Haroutunian V, Buxbaum JD, Xu H, Greengard P, Relkin NR (2000) Intraneuronal Abeta42 accumulation in human brain. Am J Pathol 156: 15-20. CrossRef Medline

Greenberg SG, Davies P (1990) A preparation of Alzheimer paired helical filaments that displays distinct tau proteins by polyacrylamide gel electrophoresis. Proc Natl Acad Sci U S A 87:5827-5831. CrossRef Medline

Grinberg LT, Rüb U, Ferretti RE, Nitrini R, Farfel JM, Polichiso L, Gierga K, Jacob-Filho W, Heinsen H (2009) The dorsal raphe nucleus shows phospho-tau neurofibrillary changes before the transentorhinal region in Alzheimer's disease: a precocious onset? Neuropathol Appl Neurobiol 35:406-416. CrossRef Medline

Hardy J, Selkoe DJ (2002) The amyloid hypothesis of Alzheimer's disease: progress and problems on the road to therapeutics. Science 297:353-356. CrossRef Medline

Heuer E, Rosen RF, Cintron A, Walker LC (2012) Nonhuman primate models of Alzheimer-like cerebral proteopathy. Curr Pharm Des 18: 1159-1169. CrossRef Medline

Jicha GA, Bowser R, Kazam IG, Davies P (1997) Alz-50 and MC-1, a new monoclonal antibody raised to paired helical filaments, recognize conformational epitopes on recombinant tau. J Neurosci Res 48:128-132. CrossRef Medline

Jin M, Shepardson N, Yang T, Chen G, Walsh D, Selkoe DJ (2011) Soluble amyloid beta-protein dimers isolated from Alzheimer cortex directly induce Tau hyperphosphorylation and neuritic degeneration. Proc Natl Acad Sci U S A 108:5819-5824. CrossRef Medline

Kaas JH, Gharbawie OA, Stepniewska I (2013) Cortical networks for ethologically relevant behaviors in primates. Am J Primatol 75:407-414. CrossRef Medline

Lacor PN, Buniel MC, Furlow PW, Clemente AS, Velasco PT, Wood M, Viola KL, Klein WL (2007) A $\beta$ oligomer-induced aberrations in synapse composition, shape, and density provide a molecular basis for loss of connectivity in Alzheimer's disease. J Neurosci 27:796-807. CrossRef Medline

LaFerla FM, Green KN (2012) Animal models of Alzheimer disease. Cold Spring Harb Perspect Med 2:a006320. CrossRef Medline

LaFerla FM, Oddo S (2005) Alzheimer's disease: $\mathrm{A} \beta$, tau and synaptic dysfunction. Trends Mol Med 11:170-176. CrossRef Medline

LaFerla FM, Green KN, Oddo S (2007) Intracellular amyloid-beta in Alzheimer's disease. Nat Rev Neurosci 8:499-509. CrossRef Medline

Lambert MP, Barlow AK, Chromy BA, Edwards C, Freed R, Liosatos M, Morgan TE, Rozovsky I, Trommer B, Viola KL, Wals P, Zhang C, Finch CE, Krafft GA, Klein WL (1998) Diffusible, nonfibrillar ligands derived from Abeta1-42 are potent central nervous system neurotoxins. Proc Natl Acad Sci U S A 95:6448-6453. CrossRef Medline

Lambert MP, Velasco PT, Chang L, Viola KL, Fernandez S, Lacor PN, Khuon D, Gong Y, Bigio EH, Shaw P, De Felice FG, Krafft GA, Klein WL (2007) Monoclonal antibodies that target pathological assemblies of A $\beta$. J Neurochem 100:23-35. CrossRef Medline 
Lasagna-Reeves CA, Castillo-Carranza DL, Sengupta U, Sarmiento J, Troncoso J, Jackson GR, Kayed R (2012) Identification of oligomers at early stages of tau aggregation in Alzheimer's disease. FASEB J 26:1946-1959. CrossRef Medline

Ledo JH, Azevedo EP, Clarke JR, Ribeiro FC, Figueiredo CP, Foguel D, De Felice FG, Ferreira ST (2013) Amyloid-beta oligomers link depressivelike behavior and cognitive deficits in mice. Mol Psychiatry 18:1053-1054. CrossRef Medline

Leung E, Guo L, Bu J, Maloof M, El Khoury J, Geula C (2011) Microglia activation mediates fibrillar amyloid-beta toxicity in the aged primate cortex. Neurobiol Aging 32:387-397. CrossRef Medline

Lourenco MV, Clarke JR, Frozza RL, Bomfim TR, Forny-Germano L, Batista AF, Sathler LB, Brito-Moreira J, Amaral OB, Silva CA, Freitas-Correa L, Espírito-Santo S, Campello-Costa P, Houzel JC, Klein WL, Holscher C, Carvalheira JB, Silva AM, Velloso LA, Munoz DP, et al. (2013) TNFalpha mediates PKR-dependent memory impairment and brain IRS-1 inhibition induced by Alzheimer's $\beta$-amyloid oligomers in mice and monkeys. Cell Metab 18:831-843. CrossRef Medline

Martin RF, Bowden DM (1996) A stereotaxic template atlas of the macaque brain for digital imaging and quantitative neuroanatomy. Neuroimage 4:119-150. CrossRef Medline

Martinez-Coria H, Green KN, Billings LM, Kitazawa M, Albrecht M, Rammes G, Parsons CG, Gupta S, Banerjee P, LaFerla FM (2010) Memantine improves cognition and reduces Alzheimer's-like neuropathology in transgenic mice. Am J Pathol 176:870-880. CrossRef Medline

Masliah E, Mallory M, Alford M, DeTeresa R, Hansen LA, McKeel DW Jr, Morris JC (2001) Altered expression of synaptic proteins occurs early during progression of Alzheimer's disease. Neurology 56:127-129. CrossRef Medline

Mattson MP (2004) Pathways towards and away from Alzheimer's disease. Nature 430:631-639. CrossRef Medline

McGowan E, Eriksen J, Hutton M (2006) A decade of modeling Alzheimer's disease in transgenic mice. Trends Genet 22:281-289. CrossRef Medline

Merrick SE, Demoise DC, Lee VM (1996) Site-specific dephosphorylation of tau protein at Ser202/Thr205 in response to microtubule depolymerization in cultured human neurons involves protein phosphatase $2 \mathrm{~A}$. J Biol Chem 271:5589-5594. CrossRef Medline

Mucke L, Selkoe DJ (2012) Neurotoxicity of amyloid $\beta$-protein: synaptic and network dysfunction. Cold Spring Harb Perspect Med 2:a006338. CrossRef Medline

Murray ME, Graff-Radford NR, Ross OA, Petersen RC, Duara R, Dickson DW (2011) Neuropathologically defined subtypes of Alzheimer's disease with distinct clinical characteristics: a retrospective study. Lancet Neurol 10:785-796. CrossRef Medline

Negash S, Bennett DA, Wilson RS, Schneider JA, Arnold SE (2011) Cognition and neuropathology in aging: multidimensional perspectives from the rush religious orders study and rush memory and aging project. Curr Alzheimer Res 8:336-340. CrossRef Medline

Nirmalan NJ, Harnden P, Selby PJ, Banks RE (2009) Development and validation of a novel protein extraction methodology for quantitation of protein expression in formalin-fixed paraffin-embedded tissues using Western blotting. J Pathol 217:497-506. CrossRef Medline

Novák M (1994) Truncated tau protein as a new marker for Alzheimer's disease. Acta Virol 38:173-189. Medline

Novak M, Kabat J, Wischik CM (1993) Molecular characterization of the minimal protease resistant tau unit of the Alzheimer's disease paired helical filament. EMBO J 12:365-370. Medline

Oddo S, Caccamo A, Kitazawa M, Tseng BP, LaFerla FM (2003a) Amyloid deposition precedes tangle formation in a triple transgenic model of Alzheimer's disease. Neurobiol Aging 24:1063-1070. CrossRef Medline

Oddo S, Caccamo A, Shepherd JD, Murphy MP, Golde TE, Kayed R, Metherate R, Mattson MP, Akbari Y, LaFerla FM (2003b) Triple-transgenic model of Alzheimer's disease with plaques and tangles: intracellular A $\beta$ and synaptic dysfunction. Neuron 39:409-421. CrossRef Medline

Oddo S, Caccamo A, Cheng D, Jouleh B, Torp R, LaFerla FM (2007) Genetically augmenting tau levels does not modulate the onset or progression of A $\beta$ pathology in transgenic mice. J Neurochem 102:1053-1063. CrossRef Medline

Oikawa N, Kimura N, Yanagisawa K (2010) Alzheimer-type tau pathology in advanced aged nonhuman primate brains harboring substantial amyloid deposition. Brain Res 1315:137-149. CrossRef Medline

Orban GA, Van Essen D, Vanduffel W (2004) Comparative mapping of higher visual areas in monkeys and humans. Trends Cogn Sci 8:315-324. CrossRef Medline

Patterson KR, Remmers C, Fu Y, Brooker S, Kanaan NM, Vana L, Ward S, Reyes JF, Philibert K, Glucksman MJ, Binder LI (2011) Characterization of prefibrillar Tau oligomers in vitro and in Alzheimer disease. J Biol Chem 286:23063-23076. CrossRef Medline

Paxinos G, Watson C (1997) The rat brain in stereotaxic coordinates, Ed 3. San Diego: Academic.

Perez-Nievas BG, Stein TD, Tai HC, Dols-Icardo O, Scotton TC, BarroetaEspar I, Fernandez-Carballo L, de Munain EL, Perez J, Marquie M, Serrano-Pozo A, Frosch MP, Lowe V, Parisi JE, Petersen RC, Ikonomovic MD, López OL, Klunk W, Hyman BT, Gómez-Isla T (2013) Dissecting phenotypic traits linked to human resilience to Alzheimer's pathology. Brain 136:2510-2526. CrossRef Medline

Philip M, Benatar M, Fisher M, Savitz SI (2009) Methodological quality of animal studies of neuroprotective agents currently in phase II/III acute ischemic stroke trials. Stroke 40:577-581. CrossRef Medline

Podlisny MB, Tolan DR, Selkoe DJ (1991) Homology of the amyloid beta protein precursor in monkey and human supports a primate model for beta amyloidosis in Alzheimer's disease. Am J Pathol 138:1423-1435. Medline

Querfurth HW, LaFerla FM (2010) Alzheimer's disease. N Engl J Med 362: 329-344. CrossRef Medline

Ramsden M, Kotilinek L, Forster C, Paulson J, McGowan E, SantaCruz K, Guimaraes A, Yue M, Lewis J, Carlson G, Hutton M, Ashe KH (2005) Age-dependent neurofibrillary tangle formation, neuron loss, and memory impairment in a mouse model of human tauopathy (P301L). J Neurosci 25:10637-10647. CrossRef Medline

Rissman RA, Poon WW, Blurton-Jones M, Oddo S, Torp R, Vitek MP, LaFerla FM, Rohn TT, Cotman CW (2004) Caspase-cleavage of tau is an early event in Alzheimer disease tangle pathology. J Clin Invest 114:121130. CrossRef Medline

Scheff SW, Price DA, Schmitt FA, DeKosky ST, Mufson EJ (2007) Synaptic alterations in CA1 in mild Alzheimer disease and mild cognitive impairment. Neurology 68:1501-1508. CrossRef Medline

Schultz C, Hubbard GB, Rüb U, Braak E, Braak H (2000) Age-related progression of tau pathology in brains of baboons. Neurobiol Aging 21:905912. CrossRef Medline

Sebollela A, Freitas-Correa L, Oliveira FF, Paula-Lima AC, Saraiva LM, Martins SM, Mota LD, Torres C, Alves-Leon S, de Souza JM, Carraro DM, Brentani H, De Felice FG, Ferreira ST (2012) Amyloid- $\beta$ oligomers induce differential gene expression in adult human brain slices. J Biol Chem 287:7436-7445. CrossRef Medline

Selkoe DJ (2011) Resolving controversies on the path to Alzheimer's therapeutics. Nat Med 17:1060-1065. CrossRef Medline

Sereno MI, Tootell RB (2005) From monkeys to humans: what do we now know about brain homologies? Curr Opin Neurobiol 15:135-144. CrossRef Medline

Serrano-Pozo A, Mielke ML, Gómez-Isla T, Betensky RA, Growdon JH, Frosch MP, Hyman BT (2011) Reactive glia not only associates with plaques but also parallels tangles in Alzheimer's disease. Am J Pathol 179:13731384. CrossRef Medline

Shankar GM, Bloodgood BL, Townsend M, Walsh DM, Selkoe DJ, Sabatini BL (2007) Natural oligomers of the Alzheimer amyloid-beta protein induce reversible synapse loss by modulating an NMDA-type glutamate receptor-dependent signaling pathway. J Neurosci 27:2866-2875. CrossRef Medline

Spillantini MG, Murrell JR, Goedert M, Farlow MR, Klug A, Ghetti B (1998) Mutation in the tau gene in familial multiple system tauopathy with presenile dementia. Proc Natl Acad Sci U S A 95:7737-7741. CrossRef Medline

Tai HC, Serrano-Pozo A, Hashimoto T, Frosch MP, Spires-Jones TL, Hyman BT (2012) The synaptic accumulation of hyperphosphorylated tau oligomers in Alzheimer disease is associated with dysfunction of the ubiquitin-proteasome system. Am J Pathol 181:1426-1435. CrossRef Medline

Thal DR, Griffin WS, Braak H (2008) Parenchymal and vascular A $\beta$ deposition and its effects on the degeneration of neurons and cognition in Alzheimer's disease. J Cell Mol Med 12:1848-1862. CrossRef Medline

Thorpe JR, Morley SJ, Rulten SL (2001) Utilizing the peptidyl-prolyl cis- 
trans isomerase pin 1 as a probe of its phosphorylated target proteins: examples of binding to nuclear proteins in a human kidney cell line and to tau in Alzheimer's diseased brain. J Histochem Cytochem 49:97-108. CrossRef Medline

Toledano A, Álvarez MI, López-Rodriguez AB, Toledano-Díaz A, FernándezVerdecia CI (2014) Does Alzheimer's disease exist in all primates? Alzheimer pathology in non-human primates and its pathophysiological implications (II). Neurologia 29:42-55. CrossRef Medline

Van Essen DC (2013) Cartography and connectomes. Neuron 80:775-790. CrossRef Medline

Van Hoesen GW, Parvizi J, Chu CC (2000) Orbitofrontal cortex pathology in Alzheimer's disease. Cereb Cortex 10:243-251. CrossRef Medline

Wischik CM, Novak M, Thøgersen HC, Edwards PC, Runswick MJ, Jakes R, Walker JE, Milstein C, Roth M, Klug A (1988) Isolation of a frag- ment of tau derived from the core of the paired helical filament of Alzheimer disease. Proc Natl Acad Sci U S A 85:4506-4510. CrossRef Medline

Wolozin BL, Pruchnicki A, Dickson DW, Davies P (1986) A neuronal antigen in the brains of Alzheimer patients. Science 232:648-650. CrossRef Medline

Yoshiyama Y, Higuchi M, Zhang B, Huang SM, Iwata N, Saido TC, Maeda J, Suhara T, Trojanowski JQ, Lee VM (2007) Synapse loss and microglial activation precede tangles in a P301S tauopathy mouse model. Neuron 53:337-351. CrossRef Medline

Zilka N, Filipcik P, Koson P, Fialova L, Skrabana R, Zilkova M, Rolkova G, Kontsekova E, Novak M (2006) Truncated tau from sporadic Alzheimer's disease suffices to drive neurofibrillary degeneration in vivo. FEBS Lett 580:3582-3588. CrossRef Medline 